OPEN ACCESS

Edited by: Nurit Hollander, Tel Aviv University, Israel

Reviewed by: Olga Matveeva, The University of Utah, United States Karim Essani, Western Michigan University, United States

${ }^{*}$ Correspondence: Yuan Lin liny96@mail.sysu.edu.cn

Specialty section: This article was submitted to

Cancer Immunity and Immunotherapy, a section of the journal Frontiers in Immunology

Received: 07 June 2021 Accepted: 16 September 2021 Published: 05 October 2021

Citation:

Zeng J, Li X, Sander M, Zhang H, Yan G and Lin Y (2021) Oncolytic ViroImmunotherapy: An Emerging Option in the Treatment of Gliomas.

Front. Immunol. 12:721830. doi: 10.3389/fimmu.2021.721830

\section{Oncolytic Viro-Immunotherapy: An Emerging Option in the Treatment of Gliomas}

\author{
Jiayi Zeng ${ }^{1}$, Xiangxue $L^{2}{ }^{2}$, Max Sander ${ }^{3}$, Haipeng Zhang ${ }^{4}$, Guangmei Yan ${ }^{5}$ and Yuan Lin $^{5 *}$ \\ ${ }^{1}$ Zhongshan School of Medicine, Sun Yat-sen University, Guangzhou, China, ${ }^{2}$ Peking University Sixth Hospital, Peking \\ University Institute of Mental Health, NHC Key Laboratory of Mental Health (Peking University), National Clinical Research \\ Center for Mental Disorders (Peking University Sixth Hospital), Peking University, Beijing, China, ${ }^{3}$ Department of International \\ Cooperation, Guangzhou Virotech Pharmaceutical Co., Ltd., Guangzhou, China, ${ }^{4}$ Department of Pharmacology, School of \\ Medicine, Jinan University, Guangzhou, China, ${ }^{5}$ Department of Pharmacology, Zhongshan School of Medicine, Sun Yat-sen \\ University, Guangzhou, China
}

The prognosis of malignant gliomas remains poor, with median survival fewer than 20 months and a 5 -year survival rate merely $5 \%$. Their primary location in the central nervous system (CNS) and its immunosuppressive environment with little $T$ cell infiltration has rendered cancer therapies mostly ineffective, and breakthrough therapies such as immune checkpoint inhibitors (ICls) have shown limited benefit. However, tumor immunotherapy is developing rapidly and can help overcome these obstacles. But for now, malignant gliomas remain fatal with short survival and limited therapeutic options. Oncolytic virotherapy (OVT) is a unique antitumor immunotherapy wherein viruses selectively or preferentially kill tumor cells, replicate and spread through tumors while inducing antitumor immune responses. OVTs can also recondition the tumor microenvironment and improve the efficacy of other immunotherapies by escalating the infiltration of immune cells into tumors. Some OVTs can penetrate the blood-brain barrier (BBB) and possess tropism for the CNS, enabling intravenous delivery. Despite the therapeutic potential displayed by oncolytic viruses (OVs), optimizing OVT has proved challenging in clinical development, and marketing approvals for OVTs have been rare. In June 2021 however, as a genetically engineered OV based on herpes simplex virus-1 (G47 approval for the treatment of malignant gliomas in Japan. In this review, we summarize the current state of OVT, the synergistic effect of OVT in combination with other immunotherapies as well as the hurdles to successful clinical use. We also provide some suggestions to overcome the challenges in treating of gliomas.

Keywords: oncolytic virus, immunotherapy, delivery, combinations, gliomas

\section{INTRODUCTION}

Gliomas, which arise from glial or their precursor/stem cells, including diffuse gliomas and nondiffuse gliomas, are the most common primary CNS tumors $(1,2)$. Approximately 100,000 people around the world are diagnosed with diffuse gliomas every year (3). Based on WHO 2016 classification, diffuse gliomas can be further classified as: diffuse or anaplastic astrocytoma, 
isocitrate dehydrogenase (IDH)-wild type; diffuse or anaplastic astrocytoma, IDH-mutant; glioblastoma (GBM), IDH-wild type; glioblastoma, IDH-mutant; and oligodendroglioma or anaplastic oligodendroglioma, IDH-mutant and $1 \mathrm{p} 19 \mathrm{q}$ co-deletion $(4,5)$. GBM, another term for WHO grade IV astrocytoma, is the most common type in adults and it is about four times more common than anaplastic astrocytoma (6). Currently, the treatment of gliomas faces great difficulties:

1. Gliomas have a poor prognosis after being treated with existing therapies (surgery, chemotherapy and radiotherapy) with median survival fewer than 20 months and a 5 -year survival rate merely $4-5 \%(7,8)$;

2. The presence of the BBB renders many conventional cancer drugs ineffective;

3. The immune-privileged environment in CNS makes immune checkpoint inhibitor therapy, which has been widely studied in recent years, less effective in gliomas (9);

Over the last decade, hopes have risen that emerging immunotherapy could improve specific immune responses against tumor cells in patients with brain tumors (10-13). Despite intensive clinical research, the FDA is yet to approve an immunotherapy for glioma.

Oncolytic Viruses can selectively or preferentially infect tumor cells and induce tumor lysis. Some of them, including parvovirus $\mathrm{H}-1$ and reovirus, can also penetrate the $\mathrm{BBB}$ and possess tropism for the CNS, enabling intravenous delivery in clinical trials $(14,15)$. Furthermore, OVs can activate the innate immune response and the adaptive anti-tumor immunity to target distant uninfected tumors cells. As of 2021, at least 15 different virus species are currently under study: adenovirus, herpes simplex virus-1 (HSV-1), parvovirus, vaccinia virus, myxoma virus, reovirus, enterovirus, measles virus, Newcastle disease virus (NDV), vesicular stomatitis virus (VSV), retrovirus, Zika virus, M1 virus, Semliki Forest virus and Seneca Valley virus.

In this review, we will summarize the state of oncolytic virotherapy and its combination with other immunotherapies in gliomas.

\section{IMMUNOSUPPRESSIVE MICROENVIRONMENT OF GLIOMAS}

The BBB consists of endothelial cells, astrocytes and pericytes, forming tight junctions to make the CNS an immune-privileged environment. In healthy individuals, most of peripheral immune cells are excluded from entering the brain (16). However, T cell entry and immunosurveillance within the brain have been documented over the years $(17,18)$.

During inflammation, particularly, microglia within the brain undergo substantial phenotypic changes, and specific macrophage populations are recruited from circulating monocytes (19). Microglia are CNS-resident myeloid cells that migrate to the developing brain early in gestation (20). They are responsible for phagocytosis and synapse formation and pruning in both healthy and pathological states $(21,22)$. More and more preclinical and clinical studies found that microglia can modulate glioma growth via facilitating proliferation, invasion and stemness of gliomas (23-26). Furthermore, microglia can promote the recruitment of T-reg cells and anti-inflammatory macrophages from systemic circulation through the release of chemokine ligand 2 (CCL2) (27). Anti-inflammatory macrophages (AIM) in gliomas have reciprocal effects with microglia on enhancing tumorigenesis (28). AIM in gliomas are also suggested to support angiogenesis and mediate glioma recurrence $(29,30)$. Therefore, glioma-associated microglia and macrophages can be developed as therapeutic targets for glioma patients (31) (Figure 1).

It is also well-documented that tumors can secrete soluble factors in high concentrations, such as vascular endothelial growth factor (VEGF) and matrix metalloproteinases (MMPs). These factors can destroy the endothelial tight junctions, degrade proteoglycans and induce numerous blood derived factors (32, 33). A significant challenge in treating brain tumors is to enable a drug to cross the BBB so the breakdown of the endothelial tight junctions can be an opportunity to deliver drugs to gliomas.

Despite increasing evidence showing that the notion of "immune-privileged" is inaccurate, brain tumors still can prevent the immunosurveillance of the CNS and foster antigenic ignorance - for example, in sphingosine 1 phosphate receptor 1 (S1PR1)-dependent fashion. S1PR1 is a G proteincoupled receptor (GPCR) that binds sphingosine-1-phosphate (S1P), a lipid second messenger. S1P-S1PR1 axis plays an important role in lymphocyte trafficking. The level of S1P1 on the surface of T-cells in GBM patients is decreased compared to healthy controls. The dysfunction of this axis results in T-cell trapping within lymphoid organs, preventing $\mathrm{T}$-cells from trafficking to the brain $(34,35)$.

Owing to the vulnerability of the brain to changes in intracranial pressure, an immunosuppressive environment inhibits the development of intracranial inflammation, including tumor-related inflammation (36). Various cells (AIMs, microglia, astrocytes) in tumor microenvironment can produce high level of immunosuppressive cytokines like transforming growth factor $\beta$ (TGF $\beta$ ) and interleukin-10 (IL$10)$ in response to inflammatory stimuli $(18,37,38)$. Glioma cells can generate a great amount of indolamine 2,3-dioxygenase (IDO) to both inhibit $\mathrm{T}$ cell activity and promote the recruitment of regulatory $\mathrm{T}$ cells (Treg) through depletion of tryptophan from the microenvironment (39). Also, glioma cells attract both microglia and AIM to enhance tumor growth and promote immunosuppression (23). A large amount of arginase can be produced by microglia and tumor-infiltrating myeloid cells to inhibit $\mathrm{T}$ cell proliferation and function by depleting tissue arginine levels $(18,40,41)$. Relatively low mutation load, little $\mathrm{T}$ cell infiltration and immunosuppressive microenvironment have been observed in GBM, making for a "cold" tumor microenvironment (10). It is generally accepted that this "cold" microenvironment makes ICIs less effective in the treatment of GBM (42). 


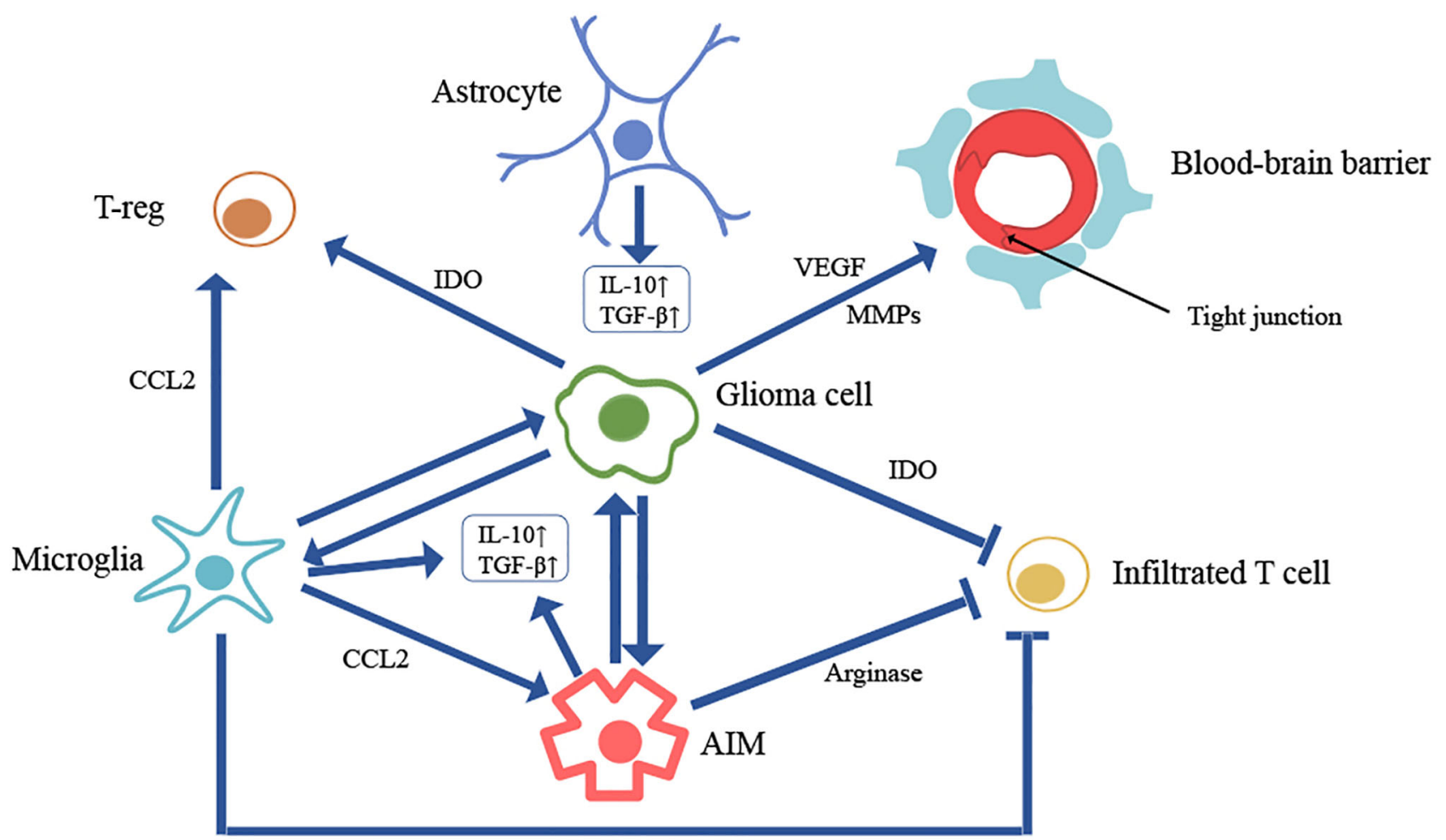

Arginase

FIGURE 1 | Cell interactions in brain tumor microenvironment. Microglia can 1) modulate glioma growth via facilitating proliferation, invasion and stemness of glioma; 2) promote the recruitment of T-reg cells and anti-inflammatory macrophages (AIM) from systemic circulation through the release of chemokine ligand 2 (CCL2); 3) produce high level of immunosuppressive cytokines like transforming growth factor $\beta$ (TGF $\beta$ ) and interleukin-10 (IL-10); 4) produce a large amount of arginase to inhibit T cell proliferation and function by depleting tissue arginine levels. AIM can 1) support tumorigenesis; 2) produce high level of immunosuppressive cytokines like TGF $\beta$ and IL-10; 3) produce a large amount of arginase to inhibit T cell proliferation and function by depleting tissue arginine levels. Glioma cell can 1) secrete soluble factors (VEGF, MMPs) to destroy the endothelial tight junctions, causing blood-brain barrier leakage; 2) generate a great amount of indolamine 2,3dioxygenase (IDO) to both inhibit T cell activity and promote the recruitment of regulatory T cells (Treg) through depletion of tryptophan from the microenvironment; 3 ) attract both microglia and AIM to enhance tumor growth and promote immunosuppression. Astrocyte can also produce high level of immunosuppressive cytokines like TGF $\beta$ and IL-10.

\section{ONCOLYTIC VIROTHERAPY FOR GLIOMAS}

\section{Oncolytic Virus}

Oncolytic viruses are an emerging class of antitumor immunotherapies. Talimogene laherparepvec ( $\mathrm{T}-\mathrm{Vec})$, a genetically engineered OV based on HSV-1, is the most prominent and the only FDA approved OV used for treating malignant melanoma (43). OVs can selectively or preferentially infect and kill tumor cells, while activating the immune system (44) (Figure 2), by the following general mechanisms:

1. OVs can selectively or preferentially infect tumor cells and induce direct tumor lysis due to the deficient or inhibited antiviral innate immunity pathways (e.g. IFN pathway) in many tumor cells $(45,46)$.

2. Tumor cell lysis due to OV infection can cause the release of tumor associated antigens (TAAs), cell-derived damageassociated molecular patterns (DAMPs) and viral pathogen-associated molecular patterns (PAMPs), which can recruit dendritic cells (DCs) and innate lymphoid cells (e.g. NK cells) for early clearance of virus-infected cells (47).

3. The release of TAAs, DAMPs, PAMPs, pro-inflammatory cytokines and chemokines by lysed tumor cells and innate immune cells can promote antigen presentation and antigenspecific adaptive immune responses $(48,49)$.

4. The immune responses kill not only infected tumor cells, but also uninfected tumor cells through bystander effects $(50,51)$.

5. OVs can promote the recruitment of tumor infiltrating lymphocytes into tumor sites, making the immunosuppressive microenvironment "hot" and suitable for other immunotherapies (52).

In the following, the particularities of these mechanisms in glioma are discussed. In glioblastoma cancer stem cells, antiviral innate immunity pathways (IFN pathway, TLR pathway) are reduced, which contributes to the tumor cell specificity of OVs (mechanism 1) $(53,54)$. Interestingly, due to the isolated location surrounded by mitotically silent normal neurons, malignant gliomas may be particularly suitable for treatment with OVs, 


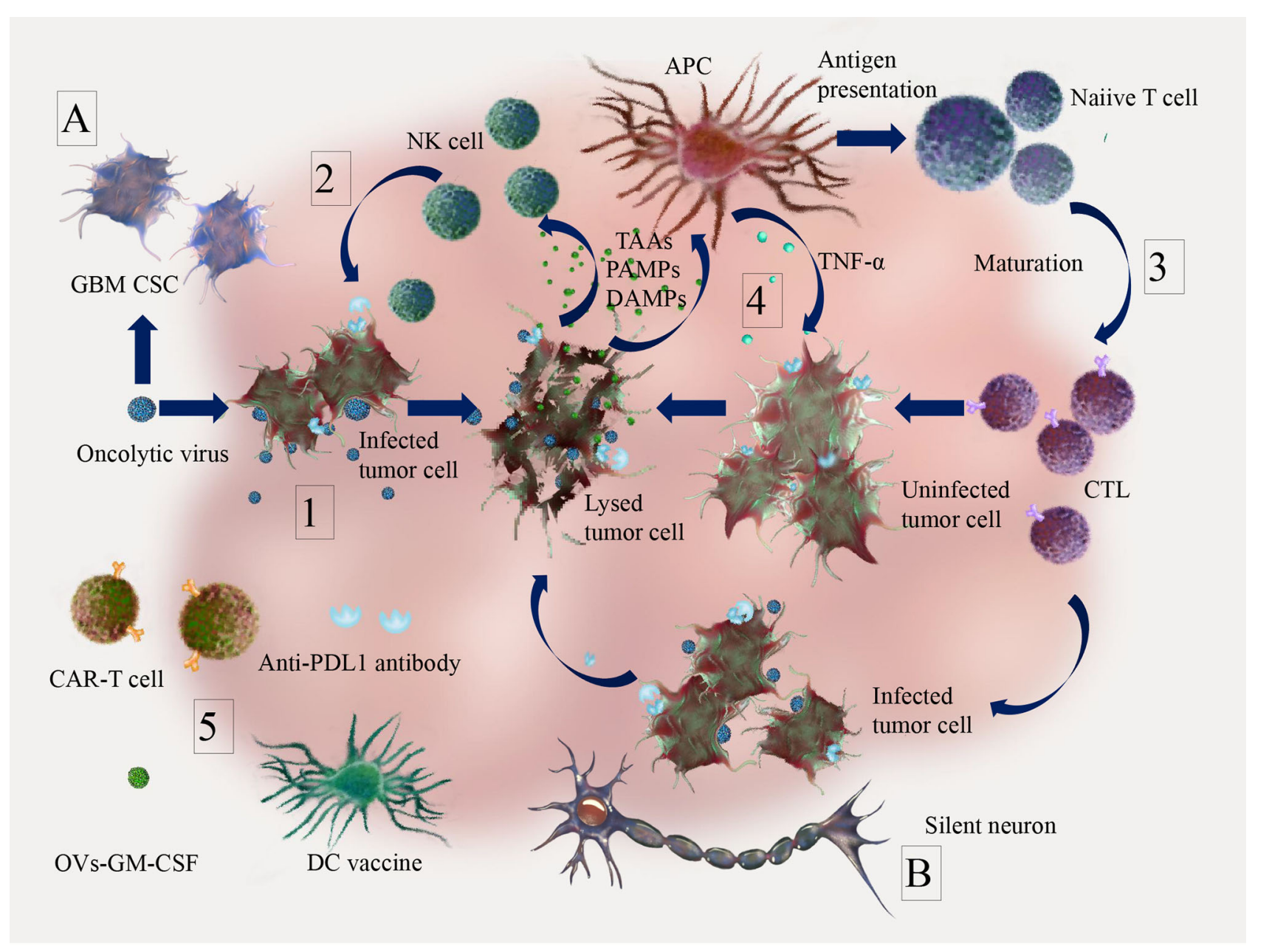

FIGURE 2 | Anti-tumor effects of oncolytic virus (OV) and combination therapy in brain tumor. 1. OVs can selectively or preferentially infect tumor cells and induce tumor lysis. 2. Innate immune response. Tumor cell lysis due to OVs infection can cause the release of tumor associated antigens (TAAs), cell-derived damageassociated molecular patterns (DAMPs) and viral pathogen-associated molecular patterns (PAMPs), which can recruit dendritic cells (DCs) and innate lymphoid cells (e.g. NK cells) for early clearance of virus-infected cells; 3. Adaptive immune response. The release of TAAs, DAMPs, PAMPs, pro-inflammatory cytokines and chemokines by lysed tumor cells can trigger activation of antigen presenting cells (APCs) and promote the priming of cellular mediated immune responses (CTL infiltration); 4. OVs infection leads to the release of TAAs, PAMPs and DAMPs, which can induce innate immune responses (e.g. secretion of TNF- $\alpha$ ) against not only infected tumor cells, but also uninfected tumor cells through bystander effects; 5 . Infection and replication of oncolytic viruses in tumors can activate anti-tumor immunity and turn "cold" into "hot" tumors, which make combination therapies such as immune checkpoint inhibitors (e.g. PD-1/PD-L1 inhibitor), adoptive cell therapy (e.g. CAR-T), tumor vaccines (e.g. DC vaccine) and immunotherapeutic modulators (e.g. GM-CSF, which can enhance the activation of NK cells and CD8mediated T cell response) more effective. For glioma specifics, (A) antiviral innate immunity pathways (IFN pathway, TLR pathway) are reduced in glioblastoma cancer stem cells (GBM CSC), which contributes to the tumor cell specificity of OVs. (B) Due to the isolated location surrounded by mitotically silent normal neurons, malignant gliomas may be particularly suitable for treatment with OVs, which require active cell cycles for their replication.

which require active cell cycles for their replication $(55,56)$. Utilizing mechanisms $2-5$, a growing body of evidence suggests that OVs can "heat" the immunologically "cold" microenvironment of GBM by inducing immunogenic cell death (ICD) and inflammation. In a large number of preclinical studies, ICD was induced by OVs, along with infiltration of cytotoxic $\mathrm{T}$ cells and reduced accumulation of myeloid-derived suppressor cells (MDSCs) $(57,58)$. Clinical studies have also shown that OVs can induce cytotoxic $\mathrm{T}$ cells infiltration and other relevant immune responses against glioma (59-61).
Further research is needed to understand mechanisms of interaction of components in the tumor microenvironment to fully exploit the potential of OVs in glioma. Modern discoveries related to the molecular mechanisms of specific OVs are discussed in paragraphs "DNA Viruses" and "RNA Viruses".

When considering OVs for glioma treatment, it is vital to exclude OVs which display neurotoxicity. With few exceptions, these viruses fall into one of two groups: 1) non-neurotoxic viruses and 2) neuro-attenuated viruses. Non-neurotoxic viruses are viruses that have not been observed to be neurotoxic and do 
not necessarily require additional engineering before being used for treatment, including parvovirus, myxoma virus, M1 virus and Seneca Valley virus (SVV) (62). Neuro-attenuated viruses are viruses with neurovirulent features that have been modified (e.g. by gene editing) to reduce neurotoxicity. Adenovirus, herpes simplex virus (HSV), VSV, poliovirus and measles virus fall under this category. The various mechanisms of viral attenuation leading to decreased neurotoxicity are discussed below.

In the case of HSV, a number of mutants were created by modifying the virus to reduce neurovirulence without affecting the virus's ability to infect actively dividing cells (63). For example, HSV-1716 and R3616 mutants have deletions in both copies of the viral $\gamma_{1} 34.5$ genes, which are necessary for neurovirulence $(64,65)$. The neurovirulence of poliovirus is attributed to the following two aspects: 1) selective binding of CD155 receptor-expressing motor neurons and 2) an internal ribosomal entry site (IRES) sequence in the viral genome. The neurotoxic poliovirus was engineered into a neuroattenuated virus by replacing the entire IRES with its nonpathogenic counterpart from human rhinovirus type 2 (66). Several mutants have been created to reduce the potential neurotoxicity of VSV in the treatment of glioma, studied in a rodent model $(67,68)$.

In this review, we will discuss 15 different virus species which are currently under study to treat gliomas. Among them, 5 are DNA viruses, while 10 are RNA viruses. Important features of these viruses have been listed in Table $\mathbf{1}$.

\section{DNA Viruses}

We have listed the current clinical trials utilizing DNA viruses against gliomas in Table 2.

\section{Adenovirus}

Adenoviruses are double-stranded-DNA viruses of the Adenoviridae family with 70-90 $\mathrm{nm}$ in size (88). The adenovirus has sufficient transgene capacity which can carry therapeutic genes of sizes of about 30-38 kb (69). A genetically modified variant, AdDelta24-RGD, also known as DNX-2401, has the ability to selectively infect glioma cells after either intratumoral or intracavitary (injection into the surgically created resection cavity) delivery (59).

Safety in patients with recurrent high-grade glioma has been demonstrated in phase I clinical trial (NCT00805376). In this study, an improved median overall survival has been shown in patients who received surgical resection as well as AdDelta24RGD. Seven patients had a long-term survival of over 24 months and no Grade 3 or greater adverse events occurred $(59,89)$. Another phase I trial demonstrated safety in patients treated with AdDelta24-RGD through convection enhanced delivery (CED), an intratumoral delivery using continuous, low-positivepressure bulk flow to deliver drugs through the implantation of catheters (90-92). AdDelta24-RGD is currently studied as a combination therapy in multiple phase I and II studies (NCT01956734, NCT02197169, NCT02798406).

CRAd-S-pk7 is an oncolytic adenoviral vector containing a survivin promoter and a $\mathrm{pk} 7$ fiber modification to selectively target glioma (93). A recent study found that it could be successfully encapsulated within mesenchymal stem cells (MSCs) as a new delivery strategy to treat diffuse intrinsic pontine glioma (DIPG), one of the deadliest brain tumors in children (94). Another phase I clinical trial using neural stem cells (NSCs) as delivery vehicles is ongoing (NCT03072134).

High levels of chronic immune activation detected in cancer patients correlate with poor prognosis in treatment with oncolytic adenovirus. Therefore, it might be necessary to screen the immune status of patients before treatment $(95,96)$.

\section{Herpes Simplex Virus}

Herpes simplex virus- 1 is a double-stranded, linear-DNA virus of the Herpesviridae family that has been widely adopted for OVT and most extensively studied (71). An advantage of HSV-1 is that it can incorporate multiple large transgenes within its

TABLE 1 | Important features about the oncolytic viruses mentioned above.

\begin{tabular}{|c|c|c|c|c|c|c|c|}
\hline Virus type & Family & Genome & Genome size & Transgene capacity & Viral immunogenicity & BBB penetration & Ref \\
\hline Adenovirus & Adenoviridae & dsDNA & $32 \mathrm{~kb}$ & High & Low & - & $(69,70)$ \\
\hline Herpes simplex virus & Herpesviridae & dsDNA & $152 \mathrm{~kb}$ & High & Low & - & $(70,71)$ \\
\hline Parvovirus & Parvoviridae & ssDNA & $5 \mathrm{~kb}$ & Low & High & + & $(70,72)$ \\
\hline Vaccinia virus & Poxviridae & dsDNA & $190 \mathrm{~kb}$ & High & High & - & $(73,74)$ \\
\hline Myxoma virus & Poxviridae & dsDNA & $161.8 \mathrm{~kb}$ & High & High & - & $(74,75)$ \\
\hline Reovirus & Reoviridae & dsRNA & $23 \mathrm{~kb}$ & Low & Low & + & $(70,76)$ \\
\hline Enterovirus & Picornaviridae & ss(+)RNA & $7.2-8.4 \mathrm{~kb}$ & Low & Moderate & + & $(70,77)$ \\
\hline Measles virus & Paramyxoviridae & ss (-)RNA & $16 \mathrm{~kb}$ & Low & Moderate & - & $(78,79)$ \\
\hline Newcastle disease virus & Paramyxoviridae & ss (-)RNA & $15 \mathrm{~kb}$ & Low & Low & + & $(79,80)$ \\
\hline Vesicular stomatitis virus & Rhabdoviridae & ss (-)RNA & $11 \mathrm{~kb}$ & Low & Low & - & $(79,81)$ \\
\hline Retrovirus & Retroviridae & ss(+)RNA & $7-10 \mathrm{~kb}$ & Moderate & Low & + & $(79,82)$ \\
\hline Zika virus & Flaviviridae & ss(+)RNA & $10.7 \mathrm{~kb}$ & Low & High & + & $(79,83,84)$ \\
\hline M1 virus & Togaviridae & ss(+)RNA & $11.7 \mathrm{~kb}$ & Moderate & Moderate & + & $(79,85)$ \\
\hline Semliki Forest virus & Togaviridae & ss(+)RNA & $13 \mathrm{~kb}$ & Moderate & Moderate & + & $(79,86)$ \\
\hline Seneca Valley virus & Picornaviridae & ss(+)RNA & $7 \mathrm{~kb}$ & Low & High & + & $(70,87)$ \\
\hline
\end{tabular}

dsDNA, double-stranded DNA; ssDNA, single-stranded DNA; dsRNA, double-stranded RNA; ss(+)RNA, positive single-stranded RNA; ss(-)RNA, negative single-stranded RNA; Transgene capacity, the maximum size of inserted foreign gene fragments, Low(<7kb), Moderate(7-10kb), High(>10kb); Viral immunogenicity, the strength of immune response to the oncolytic virus backbone and the transgene(the Low-Moderate-High comparison is based on the capacity of virus induced antibodies); BBB penetration, (+) with study validation,

(-) without study validation. 
TABLE 2 | Current clinical trials utilizing DNA viruses against gliomas.

\begin{tabular}{|c|c|c|c|c|c|c|c|}
\hline Virus type & Strain & Targeted malignancy & Routes & $\begin{array}{l}\text { Latest } \\
\text { phase }\end{array}$ & Combination therapy & Trial No. & Status \\
\hline \multirow[t]{9}{*}{ Adenovirus } & SCH-58500 & Brain tumor & IT & 1 & Conventional surgery & NCT00004080 & Completed \\
\hline & DNX-2440 & Glioblastoma & IT & 1 & & NCT03714334 & Recruiting \\
\hline & $\begin{array}{l}\text { CRad-S- } \\
\text { pk7 }\end{array}$ & Brain tumor & IC & 1 & $\begin{array}{l}\text { Neural stem cells loaded with an oncolytic } \\
\text { adenovirus }\end{array}$ & NCT03072134 & $\begin{array}{l}\text { Active, not } \\
\text { recruiting }\end{array}$ \\
\hline & DNX-2401 & $\begin{array}{l}\text { Glioblastoma/Recurrent } \\
\text { Tumor }\end{array}$ & IT & 1 & Temozolomide & NCT01956734 & Completed \\
\hline & & Glioblastoma or Gliosarcoma & IT & I & $\mathrm{IFN}-\gamma$ & NCT02197169 & Completed \\
\hline & & Recurring Glioblastoma & IT & I & & NCT00805376 & Completed \\
\hline & & Recurring Glioblastoma & IT(CED) & $1 / 11$ & & NCT01582516 & Completed \\
\hline & & Brain tumor & $\mathrm{IT}$ & $\|$ & Pembrolizumab & NCT02798406 & $\begin{array}{l}\text { Active, not } \\
\text { recruiting }\end{array}$ \\
\hline & & Recurrent Glioblastoma & $\mid A$ & 1 & & NCT03896568 & Recruiting \\
\hline \multirow[t]{9}{*}{ HSV } & C134 & Brain tumor & IT & 1 & & NCT03657576 & Recruiting \\
\hline & M032 & Brain tumor & IT & 1 & & NCT02062827 & Recruiting \\
\hline & $\begin{array}{l}\text { rQNestin } \\
34.5\end{array}$ & Brain tumor & $\mathrm{IT}$ & 1 & & NCT03152318 & Recruiting \\
\hline & G207 & Brain tumor & IT & 1 & Radiation & NCT02457845 & $\begin{array}{l}\text { Active, not } \\
\text { recruiting }\end{array}$ \\
\hline & & Brain tumor & IT & $|/| \mid$ & & NCT00028158 & Completed \\
\hline & & Pediatric brain tumor & IT & I & Radiation & NCT03911388 & Recruiting \\
\hline & & Pediatric brain tumor & $\mathrm{IT}$ & $\|$ & Radiation & NCT04482933 & Not yet recruiting \\
\hline & HSV-1716 & Pediatric brain tumor & IT & 1 & dexamethasone & NCT02031965 & Terminated \\
\hline & $\mathrm{G} 47 \Delta$ & $\begin{array}{l}\text { Residual or recurrent } \\
\text { glioblastoma }\end{array}$ & IT & $\|$ & & UMIN000015995 & Completed \\
\hline $\begin{array}{l}\text { Vaccinia } \\
\text { virus }\end{array}$ & TG6002 & Glioblastoma & IV & $1 / 11$ & 5-flucytosine & NCT03294486 & Recruiting \\
\hline Parvovirus & H-1PV & Glioblastoma & $\begin{array}{l}\mathrm{IV}, \mathrm{IT} \\
\mathrm{IC}\end{array}$ & $|/| \mid$ & & NCT01301430 & Completed \\
\hline
\end{tabular}

IT, Intratumoral; IC, Intracavitary; IV, Intravenous; IA, Intra-arterial; CED, Convection-enhanced delivery. (The data is based on "clinicaltrials.gov").

genome. In preclinical studies, by incorporating transgenes encoding immunomodulatory molecules, such as interleukin 12 (G47 $\Delta$-mIL12), oncolytic HSV-1 has been shown to greatly enhance the efficacy of treatment in a glioblastoma model (97, 98). An HSV-1 based intralesional oncolytic immunotherapy, T$\mathrm{Vec}$, has been approved by EMA and FDA to treat unresectable melanoma in adults (99).

G207 and HSV-1716 are two HSV-1 variants with the ability to target and kill glioma cells. Phase I and II trials have investigated their safety as monotherapies and combined with radiotherapy, with no serious adverse events documented (100102). In particular, a phase I clinical trial using G207 alone and with radiation to treat pediatric high-grade gliomas recently reported no dose-limiting toxicity or serious adverse events (103). In addition, an interleukin-12 expressing HSV-1, M032, is being evaluated for the safety and tolerability of the maximum dose in patients with recurrent gliomas in a phase I clinical trial (NCT02062827).

G47D is another oncolytic HSV-1 strain developed by introducing another deletion mutation to the genome of G207 (104). G47 $\Delta$ has a strong induction of antitumor immunity, and it has been shown to kill cancer stem cells derived from human glioblastoma efficiently (105). G47 $\Delta$ is greatly attenuated and therefore expected to be safer than G207 and T-Vec in normal tissues (105). Recently, a single-arm phase II clinical trial in Japan was completed to test the efficacy of G47 $\Delta$ administered stereotactically in patients with residual or recurrent glioblastoma. Side effects were limited and the 1-year-survival rate of 13 patients has reached 92.3\% (UMIN000015995) (106). Based on this phase II trial, G47 $\Delta$ (Delytact/Teserpaturev) has received conditional approval from Japan's Ministry of Health, Labour and Welfare (MHLW) as an oncolytic virotherapy for the treatment of patients with malignant glioma in Japan. This certainly represents a breakthrough for OVT in glioma and the publication of the detailed results of the Phase II trial that led to approval are eagerly awaited by the scientific community.

\section{Parvovirus}

Parvoviruses are small, single-stranded DNA viruses of the Parvoviridae family (72). One variant, $\mathrm{H}-1$, is the smallest among all OVs and it has potential for intratumoral and intravenous application. It is suitable for oncolytic virotherapy of brain tumors due to its capacity to cross the $\mathrm{BBB}(14,107,108)$. It has been shown to be effective in rat and human GBM cell lines (14). Besides, it has been shown to increase DC cross-presentation of tumor antigens in a melanoma cell line, demonstrating its ability to boost host immune reactivity (109). In glioblastoma patients, $\mathrm{H}-1$ treatment was safe and triggered immunogenic changes in the tumor microenvironment in a phase I/II clinical trial (NCT01301430) (110).

\section{Vaccinia Virus}

Vaccinia viruses are large, enveloped, double-stranded-DNA viruses of the Poxviridae family. Strong transgene capacity (up 
to $40 \mathrm{~kb}$ ), efficient life cycle and selective replication in cancer cells make vaccinia viruses very promising for use as an OVT (73). Double deleted vaccinia virus (vvDD), with deletions of the thymidine kinase and vaccinia growth factor genes to enhance the safety profile, could preferentially infect and kill both Temozolomide (TMZ) resistant human brain tumor stem cells (BTSCs) and differentiated compartments of GBMs in vitro. Therefore, vvDD can be used as an effective supplement in the treatment of glioma, particularly for GBM patients resistant to TMZ $(111,112)$.

In a recent study, vvDD, expressing the fusion protein IL15R $\alpha$-IL15 and a fluorescent protein, was used to treat murine glioma GL261 in vitro and in vivo in combination with other treatments, including chemotherapy, peptide vaccine and adoptive T cell therapy (ACT). Pre-clinical results show potent antitumor effects against brain tumors when combined with celecoxib, rapamycin and ACT (113). To date, there are no clinical trials of $\mathrm{VV}$ in patients with glioma.

\section{Myxoma Virus}

Myxoma virus (MYXV) is also a double-stranded-DNA virus of the Poxviridae family (75). MYXV infects only rabbits in nature and is non-pathogenic to humans. More importantly, MYXV can preferentially infect and kill cancer cells originating from humans (75). MYXV has shown potent oncolytic activity in experimental human gliomas and produced a synergistic effect when combined with rapamycin in an immunocompetent glioma model $(114,115)$. It can promote natural killer (NK) cell mediated lysis of malignant gliomas both in vitro and in vivo (116).

MYXV could infect and kill both TMZ-resistant and -sensitive brain tumor-initiating cells (BTICs), which retained stem-cell-like properties (117). Anti-apoptotic M011L-deficient MYXV induced apoptosis in BTICs and prolonged animal survival in an immunocompetent glioblastoma model (118). Multiple compounds, e.g. axitinib, that synergize with oncolytic MYXV against human BTICs were identified (119). In immunocompetent animal models of glioma, MYXV armed with IL15R $\alpha-247$ has been shown to be a safe and powerful agent against brain tumors when combined with other immunotherapeutic methods (120). To date, there are no clinical trials of MYXV in patients with glioma.

\section{RNA Viruses}

We have listed the current clinical trials utilizing RNA viruses against gliomas in Table 3.

\section{Reovirus}

Reovirus is a double-stranded RNA virus of the Reoviridae family and is $75-85 \mathrm{~nm}$ in size with an icosahedral capsid (76). Reolysin is a reovirus-based agent which has shown the ability to penetrate the $\mathrm{BBB}$, with specificity and oncolytic activity for glioma cells in vitro and in vivo $(15,121)$. In a preclinical glioma model, reovirus can up-regulate IFN-regulated gene expression and activate $\mathrm{PD}-1 / \mathrm{PD}-\mathrm{L} 1$ axis in tumors suggesting that the reovirus combined with ICIs may enhance systemic therapy (15).

In a phase I dose escalation trial, dose limiting toxicities were not identified and a maximum tolerated dose was not reached $(122,123)$. A current phase I study of intravenously injected reovirus combined with granulocyte macrophage colonystimulating factor (GM-CSF) is ongoing in pediatric patients with high-grade relapsed or refractory brain tumors (NCT02444546). Reolysin (Pelareoreop) has been granted orphan drug status by US FDA for the treatment of brain cancer (124).

\section{Enterovirus}

Poliovirus (PV) is a single-stranded, positive-sense RNA enterovirus of the Picornaviridae family and the cause of poliomyelitis (77). An attenuated poliovirus variant, PVSRIPO, remains oncolytic but does not cause poliomyelitis and displays no neurovirulence in nonhuman primates $(66,125)$. It has been shown in animal models that a strong inflammatory reaction against infected glioma cells was triggered after PVSRIPO inoculation $(126,127)$. In another preclinical study, PVSRIPO improved OS in glioma-bearing mice (128).

Enterovirus A71 (EV-A71) has recently been found to have the potential to treat malignant gliomas. EV-A71 can selectively

TABLE 3 | Current clinical trials utilizing RNA viruses against gliomas.

\begin{tabular}{|c|c|c|c|c|c|c|c|}
\hline Virus type & Strain & Targeted malignancy & Routes & Latest phase & Combination therapy & Trial No. & Status \\
\hline Measles Virus & MV-CEA & Brain tumor & $\mathrm{IT} / \mathrm{IC}$ & 1 & & NCT00390299 & Completed \\
\hline \multirow[t]{4}{*}{ Poliovirus } & PVSRIPO & Pediatric brain tumor & IT(CED) & I & & NCT03043391 & Recruiting \\
\hline & & Malignant glioma & IT (CED) & 1 & & NCT01491893 & Active, not recruiting \\
\hline & & Malignant glioma & IT (CED) & $\|$ & & NCT02986178 & Active, not recruiting \\
\hline & & Recurrent glioblastoma & IT (CED) & $\|$ & pembrolizumab & NCT04479241 & Recruiting \\
\hline \multirow[t]{2}{*}{ Reovirus } & REOLYSIN & Pediatric brain tumor & IV & 1 & Sargramostim & NCT02444546 & Active, not recruiting \\
\hline & REOLYSIN & Malignant glioma & $\mathrm{IT}$ & 1 & & NCT00528684 & Completed \\
\hline \multirow[t]{4}{*}{ Retrovirus } & Toca 511 & Recurrent high-grade glioma & $\mathrm{IC}$ & $\|/\|$ & 5-fluorocytosine & NCT02414165 & Terminated \\
\hline & Toca 511 & Recurrent high-grade glioma & $\mathrm{IC}$ & 1 & 5-fluorocytosine & NCT01470794 & Completed \\
\hline & Toca 511 & Recurrent high-grade glioma & IC & 1 & 5-fluorocytosine & NCT01985256 & Completed \\
\hline & Toca 511 & Recurrent high-grade glioma & IT/IV & 1 & 5-fluorocytosine & NCT01156584 & Completed \\
\hline
\end{tabular}

IT, Intratumoral; IC, Intracavitary; IV, Intravenous; CED, Convection-enhanced delivery. (The data is based on "clinicaltrials.gov"). 
infect and kill malignant glioma cells, thus inhibiting tumor growth in mice (129).

In clinical studies, intratumoral injection of PVS-RIPO in patients with recurrent WHO grade IV malignant glioma was determined to be safe and improved OS (130). Currently, a phase $\mathrm{Ib}$ pediatric clinical trial is investigating the safety and dosage of PVS-RIPO by CED in high-grade gliomas as well as other brain tumors (NCT03043391). Ongoing phase II trials are also evaluating PVS-RIPO as a monotherapy or in combination therapy with pembrolizumab (NCT02986178) (NCT04479241).

\section{Measles Virus}

Measles virus (MV) is a single-stranded, negative-sense RNA virus of the Paramyxoviridae family. Unlike the wild type MV strains, attenuated vaccine strains have adapted to bind CD46 receptor for target cell entry (78). Normal brain tissue expresses low-level CD46, but glioma cells express abundant CD46 receptors on their surface. CD46 mediates MV attachment, internalization and virus-induced cell-to-cell fusion, and the safety of MV has been established in nonhuman primates $(131,132)$.

MV-CEA is a modified MV expressing carcinoembryonic antigen (CEA). CEA can serve as a marker of viral gene expression as the virus replicates. A pre-clinical study found that MV-CEA could induce brain tumor regression and improve OS in mice (133). MV-CEA could up-regulate PD-L1 in human GBM cells, and the combination with PD-1 blockade showed an increase in CD8+ TILs and improved OS in mice (134), supporting the potential of clinical combination of $\mathrm{MV}$ with $\alpha \mathrm{PD}-1$ therapy in GBM treatment (135). A phase I clinical trial of MV-CEA for the treatment of recurrent glioblastoma multiforme found no dose limiting toxicities with MV-CEA doses up to $2 \times 10^{7}$ TCID50 (NCT00390299) (136).

Oncolytic MV encoding thyroidal sodium iodide symporter (MV-NIS) can enable in vivo tracking of MV infection and enhance therapeutic efficacy (137). Cells infected by MV-NIS can express NIS. which allows cells to actively transport iodide ions into the cells, providing a possibility for in vivo radioiodine imaging studies (138). It is possible to use NIS as a nonimmunogenic marker for viral gene expression in the future. A phase I clinical trial evaluating the safety and recommended phase 2 dose of MV-NIS for the treatment of recurrent medulloblastoma or atypical teratoid rhabdoid tumor (ATRT) in children and young adults is recruiting (NCT02962167).

\section{Newcastle Disease Virus}

NDV is a large, single-stranded, negative-sense RNA virus of the Paramyxoviridae family (80). It has the ability to induce apoptosis of host cells via mitochondrial pathway and activate the antitumor immune response via increasing TNF- $\alpha$ secretion by host immune cells $(80,139)$. NDV can kill cancer cells through lytic viral infection as well (140). In the orthotopic, syngeneic murine GL261 glioma model, survival of treated animals was significantly prolonged with 50\% long-term survival versus none in the control group. Immunogenic cell death was induced in GL261 cells after NDV infection (58).
Recombinant NDV (rNDV-p53) constructed of p53 oncolytic agent for the treatment of glioma improved the prognosis of mice with glioma due to inhibition of glioma cell growth and aggressiveness both in vitro and in vivo compared with rNDV or $\mathrm{p} 53$ alone. In addition, $\mathrm{rNDV}-\mathrm{p} 53$ could induce apoptosis of glioma cells by upregulating apoptosis-related genes, stimulating lymphocyte infiltration and cytotoxic $\mathrm{T}$ lymphocyte (CTL) responses and increasing the number of apoptotic bodies in vivo (141).

In a Phase I/II trial, intravenous delivery of the oncolytic HUJ strain of NDV (NDV-HUJ) was well tolerated in patients with recurrent glioblastoma and one patient achieved a complete response (142). Currently, there are no active clinical trials using NDV as an oncolytic agent to treat GBM.

\section{Vesicular Stomatitis Virus}

VSV is a single-stranded, negative-sense RNA virus of the Rhabdoviridae family (81). Mild or asymptomatic infection of humans, rare and low pre-existing immunity to the virus and selective replication within cancer cells render VSV promising in OVT $(143,144)$. The strong neurotoxicity of VSV glycoprotein is however a major concern. A preclinical study replaced the VSV glycoprotein with the Chikungunya polyprotein E3-E2-6K-E1 to form a chimeric virus (VSV $\Delta \mathrm{G}-\mathrm{CHIKV}$ ), which appeared safe within the CNS. Furthermore, this chimeric virus could selectively infect brain tumors and prolong survival substantially in tumor-bearing mice through intracranial injection (145). Another variant, Vesicular Stomatitis Virus (VSV- $\Delta$ M51), could infect and kill both the TMZ resistant human brain tumor stem cells (BTSCs) and the differentiated compartments of GBMs in vitro (111). Recently, a novel recombinant VSV, G protein less (GLESS)-fusion-associated small transmembrane (FAST)-VSV, demonstrated antitumor effects in animal glioma models, providing the basis for clinical trials in the future (146).

\section{Retrovirus}

Retroviruses, belonging to Retroviridae family, are $100 \mathrm{~nm}$ in diameter containing two identical single-stranded, positive-sense RNA molecules 7-10 kilobases in length (82). TOCA 511 is an Moloney murine leukemia virus (MLV), encoding the cytosine deaminase (CD) gene to improve direct tumor cell killing via local conversion of prodrug 5-fluorocytosine (5-FC) to the active 5-fluorouracil (5-FU).

In a pre-clinical study, TOCA 511 was administered intravenously or intracranially in combination with 5-FC to treat immune-competent mice bearing glioma. Long-term survival and tolerability were observed, especially in animals with preexisting immunity to the virus, suggesting the potential for repeated administration (147).

Three Phase I clinical trial utilized TOCA 511 to treat recurrent high-grade gliomas (rHGGs) were completed (NCT01156584) (NCT01470794) (NCT01985256). In contrast to the promising results of the preclinical studies and the multiyear durable responses found in rHGGs patients in phase I clinical trials, no benefit was shown in a phase III randomized 
clinical study (NCT02414165) (148-150). One probable reason is that TOCA 511 is a recombinant oncolytic MLV, which can only spread efficiently in rapidly proliferating tumor cells in transplantable mouse tumors due to the short half-life of the virus in the cytoplasmic compartment, while slow proliferation is a hallmark of human cancers (151).

In a recent study, a replication competent Foamy Virus (oFV) was constructed with the ability to infect and replicate in slowly dividing tumor cells (151). This virus showed broad cancer tropism in vitro, including glioblastoma (U251).

\section{Zika Virus}

Zika virus (ZIKV) is a single-stranded, positive-sense RNA virus of the Flaviviridae family $(83,152,153)$, most prominent for an outbreak in South and Central America that raised public health concerns globally, due to its potential to cause microcephaly in children of mothers infected during pregnancy (154). Irrespective of this concerning fact, ZIKV has oncolytic potential as it can cross the endothelial barrier and preferentially target glioblastoma stem cells (GSCs) $(155,156)$.

Preclinical findings indicate that Brazilian Zika virus strain (ZIKVBR) can selectively kill human malignant brain tumor cells (157). As it can selectively kill GSCs within the tumor, a live attenuated ZIKV vaccine candidate substantially reduced brain tumor growth and prolonged survival in vivo. Antiviral immunity, inflammation, and apoptosis of GSCs are stimulated through virus infection (158). A recent in vivo study showed that CD8+ T cells were required for ZIKV oncolytic activity and immune checkpoint inhibitors could improve the effect of OVT (159). Cytosine phosphate-guanine $(\mathrm{CpG})$ recoding of Zika viral genome can reduce virus infection kinetics in nonmalignant brain cells, but retains high infectivity and oncolysis in GSCs (160).

A study using 3 dogs bearing spontaneous CNS tumors to evaluate the safety and therapeutic effect of Brazilian Zika virus $\left(\mathrm{ZIKV}^{\mathrm{BR}}\right)$ through intrathecal injection showed shrinkage of tumor, extension of survival and improvement of clinical symptoms without negative side effect (161). Further preclinical development of ZIKA OVT is required, including determinants of ZIKA infection in tumor cells, IFN signaling as well as protein expression signatures that enable viral entry and replication (162).

\section{M1 Virus}

M1 is a positive single-strand RNA virus, belongs to Getah-like alphavirus, Togaviridae family and was isolated from Hainan province in China (85). A number of studies found that M1 has a natural tropism to tumors which can be used for oncolytic virotherapy (163-165). It has significant anticancer activity including colon, bladder and liver cancer (164). M1 is safe and nonpathogenic for nonhuman primates after multiple rounds of repeated intravenous injections (62). More importantly, M1 has the ability to infiltrate the $\mathrm{BBB}$, specifically suppress malignant glioma and prolong the survival time of glioma-bearing immunocompetent mice (166).

Infection with $\mathrm{M} 1$ induces the unfolded protein response (UPR) and subsequent autophagy. This UPR-autophagy axis can be blocked to significantly enhance the antitumor efficacy of M1 in vitro and in vivo. Expression of IRE1, a key element in the UPR pathway, is down regulated in higher-grade gliomas, suggesting favorable antitumor activity of M1in gliomas (167). No clinical trials with M1 in glioma have been conducted to-date.

\section{Semliki Forest Virus}

Semliki Forest virus (SFV) is another single-strand, positivesense RNA virus belonging to alphavirus genus, Togaviridae family. SFV VA7-EGFP, an avirulent SFV A7 (92) strain with replication-competent capacity, has been evaluated in vitro in three human glioma cell lines (U172, U251, U87) and in vivo in subcutaneous and orthotopic tumor models in BALB/c mice. The three glioma cell lines were effectively killed and intravenously administered SFV VA7-EGFP completely eradicated $100 \%$ of small and $50 \%$ of large subcutaneously implanted U87Fluc tumors. Moreover, long-term survival was observed in 16 of 17 animals $(86,168)$.

miRNA expression is cell-type restricted which can be utilized for OVT to prevent replication of OVs in healthy tissues (169). To reduce neurovirulence and to target replicating tumor cells, tissue-specific micro-RNAs (miRNAs) were incorporated into multiple alphavirus vectors (169-171). Recently, an IFN-I tolerant SFV was constructed and tested in combination with ICIs in GL261 glioma model. Increased tumor-reactive CD8+ T cell infiltration in tumor microenvironment has been observed (172). No clinical trials with SFV in glioma have been conducted to-date.

\section{Seneca Valley Virus}

Seneca Valley virus isolate 001 (SVV-001) is a single-stranded, positive-sense RNA virus belonging to Picornaviridae family. It is nonpathogenic and can selectively infect and kill tumor cells, especially tumors with neuroendocrine features (87). As for brain tumors, $\alpha 2,3$ - and $\alpha 2,6$-linked sialic acids were identified as necessary for SVV-001 infection in pediatric GBM cell lines. In an immunodeficient (SCID) mouse model of pediatric GBM, intravenous injection of SVV-001 significantly prolonged survival and completely eliminated xenograft tumors without infecting any normal cells in the brain (173). No clinical trials with SVV in glioma have been conducted to-date.

\section{OBSTACLES FACED BY ONCOLYTIC VIRUS TREATMENT OF GLIOMAS}

Although oncolytic virus therapy for gliomas is promising and many clinical trials are under way, there are still fundamental difficulties that need to be overcome:

1. Modulating OVs-mediated host immune response

2. Discerning radiographic progression from immunotherapyinduced pseudoprogression using neuroimaging;

3. Finding appropriate markers for therapeutic efficacy;

4. Identifying a suitable animal model;

5. Overcoming existing obstacles in OVs delivery 


\section{Modulating OVs-Mediated Host Immune Responses}

Pre-existing immunity was considered to be a hurdle for OVT as antibodies in peripheral blood would neutralize the virus particles and prevent OVs from reaching the tumor $(174,175)$. However, recent studies have shown that pre-existing immunity can actually boost the immune-mediated antitumor response, e.g., in NDV-immunized mice, anti-viral immunity to NDV improved tumor clearance, abscopal effects and mice survival, although virus replication within the tumor was limited (176). Even pre-existing immunity to other pathogens (tetanus) could be exploited to enhance the anticancer immune response triggered by oncolytic adenoviruses (177).

As for OVT induced immunity, finding a balance between the anti-tumor and anti-viral immunity remains a big challenge for viruses use as therapeutic agents. Immunosuppression can increase the distribution of the virus in the tumor, but it limits the ability of the immune system to kill the tumor. Strengthening the host's immune system can enhance targeting of infected tumor cells, but it also limits the virus ' distribution in the tumor site (178). An alternative strategy to prevent the injected OVs from clearance before they reach the target tissue are cell-based delivery platforms. These delivery platforms can provide shelter from the host immune response without suppression of the antitumor immune-response $(94,179,180)$.

Attenuation is a viable strategy to avoid the toxicity of OVs and hyper activation of the host's immune system. For example, the problem of high virulence and strong immunogenicity of ZIKV has been solved by creating a genetically modified attenuated vaccine variant of the virus that has low virulence and reduced immunogenicity but retains viral oncolytic activity against GBM (158).

Innate antiviral immunity is not just a hurdle for the efficacy of oncolytic viruses: type I IFNs can also play an important role in antitumor host immunity (181). In glioma, loss of type I IFN signaling promotes tumorigenesis (182). However, it is challenging to exploit enhanced type I IFN response to OV for OVT, but a number of approaches are being studied. One approach is to combine ICIs with OVT, as OVs can induce IFN release in the tumor microenvironment with upregulation of PD-L1 expression on tumor cells (70). Also, the local administration of a Semliki Forest virus encoding IL12 (SFVIL12) induces tumor-specific CTLs only when the host expresses IFN $\alpha / \beta$ receptor subunit 1 (IFNAR1) $(183,184)$.

A recent study has found that stimulator of interferon genes (STING) pathway for DNA sensing has a major role in activating the adaptive immunity (by triggering type I IFN signals) against tumors, including gliomas $(181,185)$. Cytoplasmic DNA binding with cyclic GMP-AMP (cGAMP) synthase (cGAS), which in conjunction with STING, initiates the synthesis of type I IFN by immune cells (186). Batf3-lineage DCs respond to type I IFN, which can facilitate cross-presentation of antigens to CD8+ T cells $(187,188)$. In other words, STING is an important bridge between innate antiviral and adaptive antitumor immunity. It is reasonable to hypothesize that a curative therapeutic OV would be a virus that potently activates the innate immune system to trigger the antitumor adaptive immunity and resists the following antiviral response of the host (61).

There is a growing concern that OVT may be a double-edged sword with regards to tumor immunity. OVs can activate the immune system to fight the tumor through various mechanisms such as antigen-presentation, cytokine release and gene delivery. However, a growing body of evidence suggests that these mechanisms, while activating immunity, also have immunosuppressive effects. For instance, GM-CSF recruits macrophages, but whether these macrophages are present in the form of M1 or M2 remains in question (189). Also, OVs can upregulate PD-L1 expression on tumor cells via the induction of IFN release in the tumor microenvironment, enabling tumor escape from the immune system (15). Furthermore, some OVs like the vaccinia virus and VSV possess natural immune escape mechanisms, which also have dual effects on cancer treatment $(190,191)$. These mechanisms can prevent virus particles from neutralization, increasing replication and treatment efficacy on one hand, but at the same time they may not be able to adequately activate anti-tumor immunity on the other. Simply put, OVs activate the immune system, but they also suppress it to establish themselves. This might be the main reason that the efficacy of OVTs as monotherapies, including T-Vec, is not very satisfactory. Each OV influences a unique, heterogeneous immune microenvironment. To improve OVT further, we should find the appropriate adjuvant therapy for each oncolytic virus and enhance the therapeutic effect based on the underlying mechanisms.

\section{Discerning Radiographic Progression From Immunotherapy-Induced Pseudoprogression Using Neuroimaging}

Pseudoprogression is a big challenge in the follow-up of glioma patients that remains unsolved at present. It can be detected in $10-30 \%$ of GBM patients on their first MRI, which shows oedema and sometimes contrast enhancement after undergoing radiotherapy and concurrent TMZ in the first 12 weeks (192194). The target lesions in these patients continue to grow on their first MRI and then become stable, shrink, or even disappear during the subsequent imaging follow-ups. In addition, pseudoprogression has also been observed in cancer patients undergoing immunotherapies (e.g. ICIs and OVT) due to the increased immune cell infiltration (195-197).

Pseudoprogression challenges the interpretation of results and decision-making in clinical trials (198). Steroids are commonly used to control oedema and increased intracranial pressure during the stage of pseudoprogression, but long-term use can cause substantial side-effects (199). Furthermore, steroids are likely negatively affecting any immunotherapeutic interventions due to their well-known immunosuppressive effects (200). The pathophysiology of pseudoprogression and the associated molecular changes have not been fully understood yet and require further studies.

At present, RECIST 1.1 is the gold standard for assessing treatment response in solid tumors including gliomas but has not fully succeeded in overcoming the challenge of pseudoprogression 
during immunotherapy (201). A consensus guideline, iRECIST, developed by the RECIST working group tries to address this problem (202). In addition to iRECIST, Response Assessment in Neuro-Oncology (RANO) criteria also takes pseudoprogression in gliomas into consideration (203). With the development of radiologist's expertise and further experimental tweaks, researchers are expected to overcome the problem of pseudoprogression soon (204-206).

\section{Finding Suitable Markers for Evaluating the Effectiveness of Therapy}

Currently, no validated biomarkers of OVT exist. However, some biomarkers like the components of antiviral and antitumor immune response pathways, including IFN signaling elements, cGAS-STING, retinoic acid-inducible gene I (RIG-I), melanoma differentiation-associated gene 5 (MDA5), and various Toll-like receptors (TLRs) are showing great promise in OVT (207). In a recent study, impaired immunogenicity was shown in STINGknockout cancer cells after oncolytic HSV-1 infection. In immunocompetent models, STING-knockout tumors were more resistant to treatment with oncolytic HSV-1 combined with PD-1 blockade. With a partial or complete loss-of-function STING genotype, patients may not take full advantage of OVT, at least for HSV-1 (185). Therefore, STING could potentially be used as a biomarker for the screening of patients to identify those who can benefit from OVT. A logical next step is to analyze the expression of genes involved in the STING pathway in glioma patients and the effect of STING pathway in other OVTs.

In addition to cGAS/STING pathway for foreign DNA sensing, cells equipped with RIG-I/MDA5 pathway, which mainly serve for foreign RNA sensing (208). Both RIG-I and MDA5 have been observed to trigger a robust innate immune response against various tumors and effectively counteracts tumor cell heterogeneity, especially in human primary GBM (209-212). TLRs are the most widely studied pattern-recognition receptors. Targeting TLRs can have anti-tumor activity by promoting antigen presentation and activating innate and adaptive immunity $(213,214)$. All three, RIG-I, MDA5 and TLRs can be activated by some OVs, providing the possibility for combining agonist of these receptors with OVs (215-219). However, the combination therapy has to avoid sensitizing the patient to a cytokine shock-like response induced by IV delivery of OVs (220). Also, some receptors like TLRs are expressed on glioma cells with tumor-promoting properties, which should be taken into account when developing agonists into cancer immunotherapeutic (221).

Several other potential biomarkers are under investigation, including the number, density and localization of immune cells (NK cells, DCs, $\mathrm{T}_{\text {reg }}$ cells, $\mathrm{CD} 4^{+} / \mathrm{CD}^{+} \mathrm{T}$ cells), the levels of checkpoint molecules (PD-L1, CTLA-4, LAG-3), the presence of viral antigens in tumors and other pathways like IRE1 $(15,74$, 134, 167, 222, 223).

Currently, since OVT biomarkers in glioma have not been validated in clinical trials, they usually do not affect trial enrollment. OVs are not usually based on specific markers because they are not just targeting one molecule during the infection. The complex mechanism of OV makes the prospective use of a single marker insufficient to assess the therapy success.

Using OVs with knowledge of the specific mechanisms of their action will greatly benefit the OVT: appropriate markers can provide information about whether these mechanisms are working or not. More details on potential biomarkers for OVs in GBM were recently reviewed by Stavrakaki et al. (224).

\section{Identifying a Suitable Animal Model}

Clinical trials are guided by preclinical studies. Therefore, it is very important to apply the models that are most suitable for clinical research. An ideal experimental model of glioma should meet the following requirements: 1) tumor microenvironment that resembles human tumors in the brain; 2) genetic background that is similar to human gliomas; 3) a welldeveloped immune system that resembles human immunity; 4) intratumoral heterogeneity; 5) manipulability; 6) reproducibility; 7) cost-effectiveness; 8) ethical compliance (225). Currently, the majority of the preclinical studies for glioma include syngeneic models, xenografts models, genetically engineered models (GEMs) and resection models. Although each has different advantages and disadvantages, none of them can meet all of the above requirements (226-231).

It is worth mentioning that established glioma cell lines and primary glioma tumors (highly heterogenous) have substantial differences in both genomic alterations and gene expression, indicating that glioma cell lines may not be an ideal model system for primary gliomas (232). Until now, rodents have been commonly used for most preclinical studies, however, they are not the best models for assessing OVT. Some OVs are speciesspecific and unable to efficiently infect and replicate in murine cells (e.g. human specific adenoviruses) (233). Consequently, the use of xenografts may offer a solution to this problem, but the complexity of the tumor microenvironment is not reproduced. A study using Syrian hamster as an immune-competent model found that this model could support the replication of both human-adenovirus and vaccinia virus.

New glioma models are emerging that provide more opportunities for preclinical research. These models include new ways of organizing cells outside the body, such as organoids, that better mimic natural gliomas. They also include new organisms such as zebrafish, fruit flies and dogs (234-237).

\section{Overcoming Existing Obstacles in OVs Delivery}

Current delivery approaches include local delivery (intracavitary, intrathecal, and intratumoral delivery) and systemic delivery (intravascular delivery) (238).

Many OVs have been studied in patients with glioma by intracavitary or intratumoral injection, including HSV-G207, HSV-1716, adenovirus-d11520 (ONYX-015) and reovirus. Intracavitary delivery is an established way to treat gliomas, but it has been limited by the poor penetration ability of drugs reaching only tumor cells adjacent to the surgical cavity. Therefore, intracavitary delivery usually requires a maximal surgical resection (239). Intratumoral delivery is the primary 
way for most oncolytic viruses in clinical trials of glioma treatment, including adenovirus, herpes simplex virus, measle virus and enterovirus (240). Studies show that intratumoral injection can not only induce tumor lysis in the injected region but also trigger systemic antitumor immunity of the whole body (59, 123). Direct injection of oncolytic viruses into tumors primes $\mathrm{T}$ cells specific to virus components as well as tumor cells and induces local inflammation. This inflammatory condition allows recruitment of more $\mathrm{T}$ cells, thus promoting recognition and destruction of tumors (241). Intratumoral delivery requires careful patient selection, and technically challenging neurosurgery, limiting repeat administration (Figure 3) (15). Another challenge is to balance the degree of local immunosuppression which is discussed in section "Modulating OVs-Mediated Host Immune Responses" CED is an intratumoral delivery using continuous, low-positivepressure bulk flow to deliver drugs through the implantation of catheters. The difficulty of delivering repeated doses and the uncertainty in achieving meaningful drug concentrations throughout the brain makes this approach challenging (92). In the future, OVT may be based on local, image-guided delivery, which will allow direct visualization of the injection site, maximizing the availability and potential effectiveness of the OVs (242).

Systemic vascular delivery is becoming an option for more and more OVs. Current studies have found that several viruses, including reovirus, vaccinia virus, Newcastle disease virus, parvovirus $\mathrm{H}-1$, chimeric vesicular stomatitis virus, and M1 virus are able to infect brain tumors in animal models after systemic vascular delivery (61). In addition, clinical studies demonstrated that parvovirus $\mathrm{H}-1$ and reovirus can reach the brain after systemic delivery $(15,60,110)$. Compared with local delivery of OVs, systemic delivery can better stimulate immune responses throughout the body, particularly in metastasis. Because of the known heterogeneity of tumor cells, it is important to stimulate antitumor responses to a wide range of tumor associated antigens (TAAs) (243). However, there are many difficulties associated with systemic delivery that have yet to be overcome (Figure 3):

1. The intact $\mathrm{BBB}$ is able to block the passage of most viruses;

2. Even if the BBB is disrupted, the host immune system outside the CNS can neutralize the viruses;

3. Off target effects may lead to the infection of host tissue.

Pre-clinical studies have demonstrated that low-intensity pulsed ultrasound in combination with systemically injected microbubbles could temporarily open the $\mathrm{BBB}$ in a localized manner (244). This concept is currently undergoing clinical trials, and has already demonstrated safety and tolerability in patients, and therefore may provide enhanced systemic OV delivery capabilities $(245,246)$.

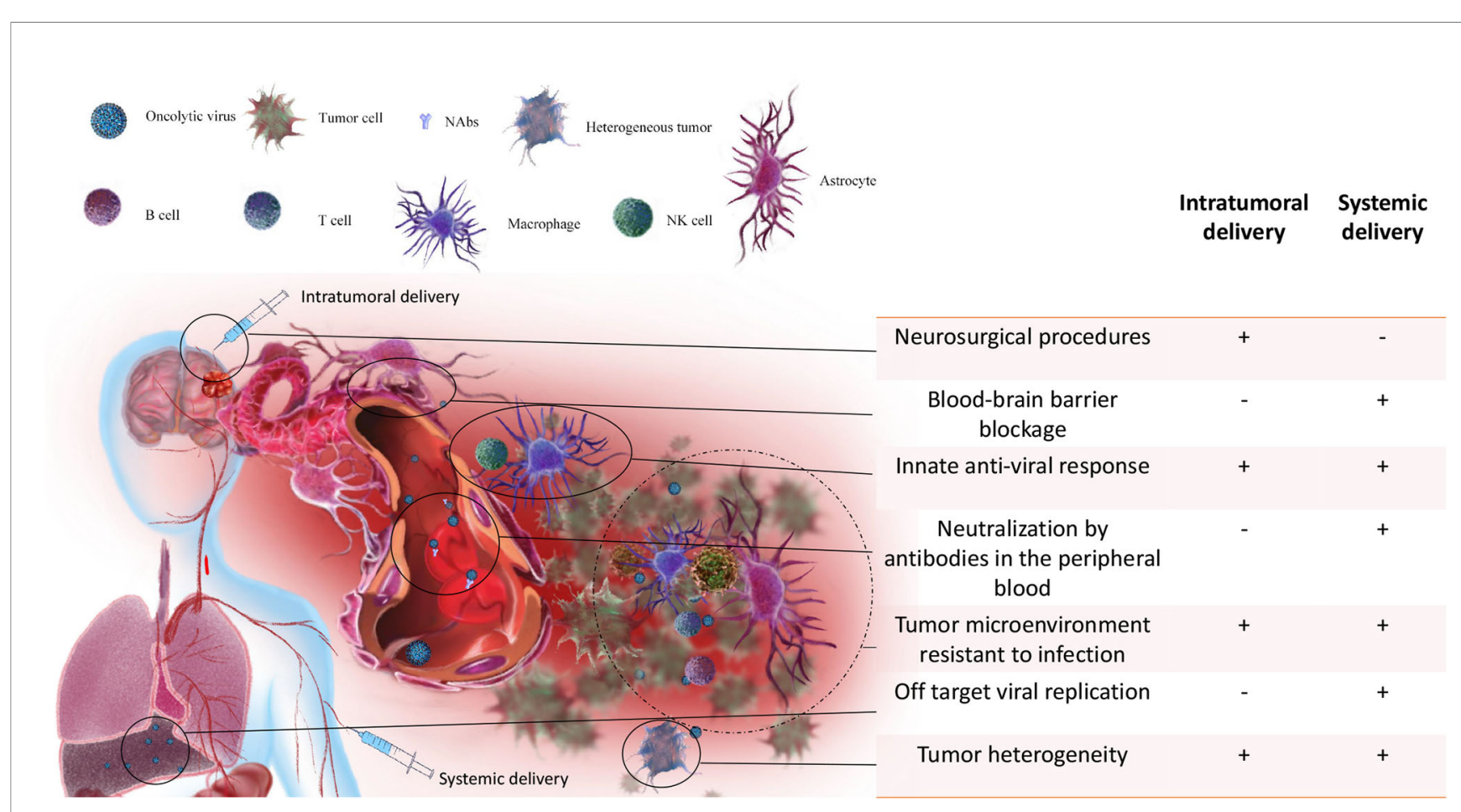

FIGURE 3 | Obstacles to OVT of gliomas via intratumoral and systemic delivery. For intratumoral delivery only, 1) the expense and complexity of neurosurgical procedures, limiting repeat administration. For systemic delivery only, 1) After injection, the first challenge is neutralization of OVs by antibodies in the peripheral blood; 2) Off target effect is the second challenge for systemic delivery since OVs may not be able to reach to the brain and cause infection to normal tissue (e.g. liver); 3) even if OVs can reach to the brain, the intact BBB is able to block the passage of most viruses. For both intratumoral and systemic delivery, 1) Innate antiviral response can prevent OVs from interacting with tumor cells; 2) the specific tumor microenvironment is also resistant to OVs infection and suppresses the OVsinduced anti-tumor immune response; 3) tumor heterogeneity can make OVs insensitive to part of tumor cells. 
It is worth paying attention to antiviral antibodies that already exist in patients, as they can be an obstacle to the systemic delivery of the virus. Cellular carriers can protect some OVs (eg, reovirus) from neutralizing antibodies (76). However, more and more studies show that preexisting immunity to OVs can enhance their therapeutic efficacy by inducing a more robust antitumor immune response, which has been observed not only with systemic delivery, but also with local delivery $(176,247)$.

Recently, a peptide-delivery platform for targeting malignant brain tumor in an immunocompetent syngeneic murine GBM model was developed. The approach enhanced targeted OV delivery and therapeutic efficacy (248). It is promising that with more clinical evidence in the future, negating the requirement for repeated invasive cranial procedures, systemic delivery may provide safer and more effective access to gliomas.

There is a shared problem of both local and systemic deliveries: the heterogeneous genotype/phenotype makes the tumor microenvironment challenging for viral replication (249). Diverse levels of IFN response in tumor microenvironments due to tumor heterogeneity make tumor cells in which the antiviral pathway is functioning well, insensitive to OV (250). The combination of several oncolytic viruses, as well as the combination of $\mathrm{OV}$ and other immunotherapies based on a different anti-tumor mechanism, may be a viable approach to address the problem of tumor heterogeneity. Overall, multiple approaches are currently undergoing clinical trials to overcome significant difficulties in efficient OV delivery to the CNS.

\section{COMBINATION WITH OTHER IMMUNOTHERAPIES}

Immunotherapy is a well-established cancer therapy. The following types of immune therapies are used in clinics for treating brain tumors: immune checkpoint inhibitors, antitumor vaccines, adaptive T-cell transfer and cytokines (251). Gliomas have immunosuppressive microenvironments, that limits the effectiveness of traditional immunotherapy. The infection and replication of oncolytic viruses in tumors can activate the anti-tumor immunity and turn "cold" tumors into "hot" ones (252). More and more evidence suggest that oncolytic viruses can enhance the effect of immunotherapy. In preclinical studies, many OVs launched an effective antitumor response against TMZ resistant glioma $(111,117)$. Also, non-overlapping mechanisms have been found between OVs and other immunotherapies (253). These findings suggest that there may be no cross-resistance to OVs and other glioma treatment.

\section{Immune Checkpoint Inhibitors}

Immune checkpoint inhibitors (ICIs) are monoclonal antibodies that inhibit cytotoxic T lymphocyte antigen 4 (CTLA4) or PD1 and its ligand PDL1 to reactivate the immune system against tumor (254). Several phase III clinical trials of ICIs for the treatment of glioblastoma are underway, including therapy with ipilimumab to block CTLA-4 and nivolumab to block PD-1 (NCT02017717, NCT02617589). However, in the treatment of patients with recurrent GBM, no significant differences in overall survival (OS) were shown when comparing nivolumab (anti-PD1) and bevacizumab (antiVEGF) (255). Brain metastases respond better to ICI compared to primary brain tumors (NCT02320058). Probable reasons for the limited response to ICIs are: relatively low mutant load, little $\mathrm{T}$ cell infiltration and immunosuppressive microenvironment in GBM (10). In addition, infiltrating PD-1-expressing T cells are rare in GBM, and tumor cells rarely express PD-L1, making for a "cold" tumor microenvironment (9).

OVs can enhance the immune responses by increasing infiltration of immune cells to tumors and improve the efficacy of ICIs, thus reconditioning the tumor microenvironment and transforming a "cold" tumor microenvironment into a "hot" one $(52,252)$. Studies suggest that OVs can be used to prime the immune response initially to create a 'hot' tumor microenvironment and make brain tumors sensitive to subsequent ICIs treatment $(15,256)$. Moreover, OVs can upregulate PD-L1 expression on tumor cells via the induction of IFN release into the tumor microenvironment, thus improving the therapeutic response to ICIs (15). Also, OVs can be engineered to express PD-L1 inhibitors, which can activate tumor neoantigen-specific $\mathrm{T}$ cell responses (257). In an immunocompetent mouse model of glioma, OVs combined with ICI have shown promising results. Among these viruses in combination with anti-PD-1 were tested adenovirus Delta-24RGDOX, HSV (G47D-mIL12), VSV, reovirus, and measles virus (134, 258-260).

Of note, a multi-institution randomized clinical trial using neoadjuvant anti-PD-1 immunotherapy for the treatment of recurrent glioblastoma has shown positive results. The trial was conducted by The Ivy Foundation Early Phase Clinical Trials Consortium. OS was significantly longer for neoadjuvant plus adjuvant pembrolizumab compared to adjuvant pembrolizumab alone. Interferon- and $\mathrm{T}$ cell-related gene expression was upregulated while cell cycle-related gene expression was downregulated within the tumor only in the neoadjuvant group (261). All these findings suggest that scheduling of ICI and OV therapy might be of major advantage and should be explored in future trials. Overall, ICIs are the most promising therapy for combination with oncolytic viruses. Since ICIs can affect $\mathrm{OV}$-induced antiviral and antitumor immunity, further studies of the immune responses triggered by these agents could significantly contribute to the development of OV plus ICI combination therapy (61).

\section{Cancer Vaccines}

There are several types of cancer vaccines, including cell-based, protein, peptide, and genetic vaccines (249). Cancer vaccines against brain tumors have broad application potential. However, most tumor vaccines fail to recruit sufficient $\mathrm{T}$ helper cells and display reduced MHC II epitope on DC surfaces, thus lacking support to the enhancement of antitumor T-cell immunity (262, 263). The search for an optimal strategy for the use of antitumor vaccines to enhance antitumor $\mathrm{T}$-cell immunity is the main direction of research in this area. The combination of vaccines with oncolytic viruses is a promising therapeutic approach, since $\mathrm{T}$-cell immunity can be further improved with virotherapy (264). 


\section{Dendritic Cell Vaccines}

In phase I and II trials, DC vaccines increased cytokine production in patients with gliomas after treatment and improved survival (265). The most advanced DC vaccine currently in clinical trials is ICT-107, which has been shown to be safe and effective. In a phase II study of 124 patients with brain tumors, compared with a control group, ICT-107 significantly improved progression-free survival (PFS) while maintaining QoL (quality of life) $(266,267)$. To maximize the immunogenicity of DCs, the focus is on optimizing the culturing conditions for DC generation in vitro (268). Additionally, preclinical studies have shown that oncolytic HSV-1 in combination with immature myeloid dendritic cells (iDCs) can reduce tumor volume and prolong survival by enhancing antitumor immunity in murine malignancies. OVs have the potential to enhance the therapeutic effects of cancer vaccines in combination therapy (269-273).

\section{Peptide Vaccines}

A specific tumor antigen that can be targeted by peptide vaccines can be represented by the following genes EGFRvIII, IDHR132H, Wilms tumor 1 (WT1) and survivin. In a phase II trials, a peptide vaccine targeting EGFRvIII improved survival in glioblastoma substantially, but the effect could not be replicated in a randomized phase III trial $(8,274)$. In a non-randomized trial, another peptide vaccine against WT1 improved the survival of patients with glioblastoma by stimulating the anti- WT1 IgG responses (275). Further, in a preclinical study, synthetic long peptides (SLPs) combined with oncolytic Maraba virus (MG1E6E7) showed a significant anti-tumor effect against advanced HPV positive neoplasia. MG1-E6E7 expresses a tetravalent transgene, which is based on attenuated viral oncogenes E6 and E7 from HPV16 and 18. HPV-associated cancers may become an attractive target for peptide vaccination through the expression of these transforming viral oncogenes. MG1-E6E7 substantially enhanced the specific CD8+ immune responses induced by SLP vaccination (276). It is expected that the combination with $\mathrm{OV}$ will soon be tested on gliomas. However, antigenic loss is a substantial obstacle to singlepeptide vaccinations. For example, several studies have shown that most patients gradually lost EGFRvIII expression after treatment, leading to tumor recurrence (274). Therefore, multipeptide vaccines may be required to target glioma variable antigens to improve treatment efficacy $(277,278)$.

Recently, phase I clinical trials of glioblastoma have shown that neoantigens vaccines can induce intratumoral $\mathrm{T}$-cell responses (279). This could represent an interesting alternative approach to improve the effectiveness of OVT treatment in glioma.

\section{Adoptive Cell Therapy}

ACT holds considerable promise for the treatment of brain tumors. T cells are extracted from patients, cultured and proliferated in vitro to improve their ability to recognize and kill tumor cells, and then injected into patients. ACT includes tumorinfiltrating lymphocytes (TILs) and genetically engineered T cells. TILs have been reported to induce regressions in some tumor types, but it is difficult to isolate and expand TILs from the CNS (18). The administration of autologous CMV-specific T cells offer a new way to treat brain tumors (280). However, chimeric antigen receptor (CAR) $\mathrm{T}$ cells therapy for brain tumors still faces significant challenges, such as heterogeneity of target antigens in tumor cells, induction of compensatory immunosuppressive response in the brain and failure to recruit infused $\mathrm{T}$ cells into brain tumors (281-284). Better strategies are needed to assist $\mathrm{T}$ cells in efficient infiltration, overcoming the immunosuppressive GBM microenvironment and handling the immune-related complications associated with ACT (10).

Combination with emerging OVs offers massive opportunities for ACT to overcome these obstacles. OVs can assist in the recruitment and activation of selected or engineered $\mathrm{T}$ cells in the tumor bed (285). Also, OVs can up-regulate the expression of MHC class I molecules by tumor cells, which can improve the targeting of ACT to tumor-specific antigens (286). In murine neuroblastoma models, arming adenovirus with the chemokine like CCL5/RANTES and the cytokine IL-15 not only preserved their oncolytic effects but also enhanced the migration and proliferation of the tumor- associated ganglioside GD2 CAR T cells, thereby increasing overall survival $(287,288)$.

Unexpectedly, another pre-clinical study demonstrated that $\mathrm{OV}$-associated type I IFN response has negative effect on CAR T cell therapy (289). The inflammatory environment generated by the oncolytic viruses and the remodeling of the tumor microenvironment neither helped in recruiting CAR $\mathrm{T}$ cells nor enhanced their functionality. The concentration of type I IFN in the tumor was inversely correlated with the number of the CAR T cells. Furthermore, IFNAR1 knock out CAR T cells showed resistance to the negative effects caused by OVs in the setting of lymphodepletion or NK cell depletion. A solution may be to limit the type I IFN signaling associated with an OV or making CAR T cells insensitive to type I IFN. Serving as soluble type I IFN decoy receptor, the expression of B18R gene in vaccinia virus may improve the combination of oncolytic vaccinia virus with CAR $\mathrm{T}$ cells in a TC1-mesothelin model $(289,290)$. Negative effects on ACT efficacy are not the only effects of type 1 IFN that can be caused by OV in tumor. There may be other effects as well. The key role of type I IFN in tumors should be considered more broadly with OV re-dosing when the endogenous $\mathrm{T}$ cell compartment may be depleted. For the time being, there are few experimental studies on the combination of ACT with oncolytic viruses in gliomas. However, these studies show that the combined approaches of OV and CAR T cells are promising for the treatment of brain tumors.

\section{Immunotherapeutic Modulators}

Multiple OVs have been armed with different anti-tumor cytokines to activate the tumor microenvironment and enhance anti-tumor immunity induced by OVs (98).

IL-12 can produce multifaceted anti-tumor effects but has been shown to have serious adverse effects when administered intravenously $(291,292)$. Recent studies found that OVs can limit the systemic toxicity of IL-12 by expressing IL-12 locally in the tumors as well as in the brains of non-human primates (293, 
294). In a murine GSC model, oncolytic HSV-1 encoding IL-12 (HSV-1-IL-12) replicated in GSCs in vitro and enhanced survival of syngeneic mice bearing GSC-derived tumors in vivo. Furthermore, HSV-1-IL-12 can activate anti-tumor immune response through increasing IFN $-\gamma$ release and reducing the number of regulatory $\mathrm{T}$ cells in the tumor (98). At present, in a phase I clinical trial, an engineered HSV-1 expressing IL-12, to treat recurrent glioma is recruiting volunteers (NCT02062827).

The gene for granulocyte macrophage colony stimulating factor (GM-CSF) has been used in several OV constructs. GMCSF enhances the activation of NK cells and CD8-mediated T cell response downstream in OVT by promoting maturation of monocytes in DCs and improving the DC's ability to present antigens $(295,296)$. Many other constructs are also being investigated, including HSV-1-IL-4, VACV-CCL5, VSV-IFNg and VSV-IL-15, ADV-IL-15 (259, 270, 297-301). There is no doubt that OVs encoding immunotherapeutic modulators for the treatment of malignant gliomas will become more and more popular in clinical studies.

\section{FUTURE DIRECTIONS}

Because of the complex interactions between the tumor and its host, gliomas remain lethal and conventional therapies have improved little in recent years. Gliomas are heterogeneous tumors and tend to be difficult to target for immunotherapy since they contain few mutations (18). Immunotherapy can only be successful if its effect reaches the brain and overcomes the difficulties associated with tumor heterogeneity and tumor targeting. The most significant result of OVT clinical trials is that this therapy is well tolerated by patients with glioma and has relatively rare serious side effects. Overall, OVT offers a selective, innovative and safe approach to treating glioma (44). Furthermore, antigen-specific $\mathrm{T}$ cells in gliomas display an exhausted phenotype $(302,303)$. OVs have the potential to change the phenotype of $\mathrm{T}$ cells from exhausted to activated type and provide more possibilities for the combination of an oncolytic virus with other immunotherapies (59). However, the mechanisms of interaction between tumor, host and OVs in brain tumor microenvironments have not been fully elucidated. Further study is needed to maximize the efficacy of OVs.

As discussed in section "Modulating OVs-Mediated Host Immune Responses", OVT may be a double-edged sword because OVs can not only activate the immune system but also suppress it to establish themselves. Different viruses can create different tumor microenvironments. Therefore, in the future, improving OVT by finding the appropriate adjuvant therapy for each $\mathrm{OV}$ and enhancing the therapeutic effect considering the underlying mechanisms should be the norm. In principle, two ways can be used to achieve this: combination therapy and arming the OV with adjuvant factors.

At the same time, personalized therapeutic approaches are becoming feasible for OVT. An ideal combination of appropriate viruses could be chosen according to the type, stage and biomarker expression of glioma. The success of oncolytic virotherapy may not only require careful screening of patients based on different mutations and protein expression in their tumors, but also require the selection of suitable OVs for a particular tumor. An ex vivo $3 \mathrm{D}$ tumor model generated from fresh tissue provides a culture condition that supports further researches into the dynamics of viral infection and the interaction with local immune system in the specific tumor microenvironment (304). With application of this system, it is possible to screen multiple OVs for a specific patient and establish the optimal OVT (224). Undoubtedly, identifying the optimal dosing, route of administration and schedule in OVs treatment requires further investigation. The sequence of application of different agents involving OVs is still under investigation. Well-designed clinical trials will pave the way for suitable, effective, and precise $\mathrm{OV}$ glioma treatments in the future.

Approaches are being developed that combine oncolytic virotherapy and many other types of immunotherapies. As two or more agents are combined, there is always a concern about the increased overall toxicity. Therefore, it is important to find more synergistic combination therapy modalities and to further understand the mechanisms of each therapy and clinical effects on immune response (305). Currently, more and more combinatorial clinical studies are under way, which undoubtedly indicates that the application of oncolytic viruses in glioma has great prospects (Tables 2, 3).

\section{CONCLUSIONS}

The development of OV for the treatment of gliomas has been going on for over two decades, and the potential of this therapy is being recognized in an increasing number of studies. As a special immunotherapy, OVT can not only kill gliomas directly, but can also activate the body's effective anti-tumor immunity, which can cause a synergistic effect with other immunotherapeutic methods. However, much remains to be learned about OVT and combination therapy, including the mechanisms that mediate the immunosuppressive microenvironment of brain tumors, optimal OVs intratumoral delivery, selection of most appropriate OVs and immune targets for different tumors, and molecular markers for prediction of therapeutic efficacy. The approval of G47D (Delytact/Teserpaturev) for the treatment of glioma in Japan, although time-limited and conditional, is the culmination of decades of OVT research in glioma. Undoubtedly, oncolytic viro-immunotherapy of gliomas has great prospects and, in the future, will have a great impact on cancer therapy.

\section{AUTHOR CONTRIBUTIONS}

JZ: Conceptualization and writing and editing of the manuscript draft. XL: Drawing of the electronic illustrations. MS: Review and language editing of the manuscript. HZ: Review of the manuscript. GY: Instruction and review of the manuscript. YL: 
Instruction and review and editing of the manuscript draft. All authors contributed to the article and approved the submitted version.

\section{FUNDING}

This research was funded by National Natural Science Foundation of China (grant number 81973347), Guangdong

\section{REFERENCES}

1. Weller M, Wick W, Aldape K, Brada M, Berger M, Pfister SM, et al. Glioma. Nat Rev Dis Primers (2015) 1:15017. doi: 10.1038/nrdp.2015.17

2. Lee DY, Gianino SM, Gutmann DH. Innate Neural Stem Cell Heterogeneity Determines the Patterning of Glioma Formation in Children. Cancer Cell (2012) 22(1):131-8. doi: 10.1016/j.ccr.2012.05.036

3. Bray F, Ferlay J, Soerjomataram I, Siegel RL, Torre LA, Jemal A. Global Cancer Statistics 2018: GLOBOCAN Estimates of Incidence and Mortality Worldwide for 36 Cancers in 185 Countries. CA Cancer J Clin (2018) 68 (6):394-424. doi: 10.3322/caac.21492

4. Molinaro AM, Taylor JW, Wiencke JK, Wrensch MR. Genetic and Molecular Epidemiology of Adult Diffuse Glioma. Nat Rev Neurol (2019) 15(7):405-17. doi: 10.1038/s41582-019-0220-2

5. Louis DN, Perry A, Reifenberger G, von Deimling A, Figarella-Branger D, Cavenee WK, et al. The 2016 World Health Organization Classification of Tumors of the Central Nervous System: A Summary. Acta Neuropathol (2016) 131(6):803-20. doi: 10.1007/s00401-016-1545-1

6. Lapointe S, Perry A, Butowski NA. Primary Brain Tumours in Adults. Lancet (2018) 392(10145):432-46. doi: 10.1016/S0140-6736(18)30990-5

7. Gittleman H, Cioffi G, Vecchione-Koval T, Ostrom QT, Kruchko C, Osorio DS, et al. Descriptive Epidemiology of Germ Cell Tumors of the Central Nervous System Diagnosed in the United States From 2006 to 2015. J Neurooncol (2019) 143(2):251-60. doi: 10.1007/s11060-019-03173-4

8. Weller M, Butowski N, Tran DD, Recht LD, Lim M, Hirte H, et al. Rindopepimut With Temozolomide for Patients With Newly Diagnosed, EGFRvIII-Expressing Glioblastoma (ACT IV): A Randomised, DoubleBlind, International Phase 3 Trial. Lancet Oncol (2017) 18(10):1373-85. doi: 10.1016/S1470-2045(17)30517-X

9. Buerki RA, Chheda ZS, Okada H. Immunotherapy of Primary Brain Tumors: Facts and Hopes. Clin Cancer Res (2018) 24(21):5198-205. doi: 10.1158/1078-0432.CCR-17-2769

10. Wang J, Shen F, Yao Y, Wang LL, Zhu Y, Hu J. Adoptive Cell Therapy: A Novel and Potential Immunotherapy for Glioblastoma. Front Oncol (2020) 10:59. doi: $10.3389 /$ fonc.2020.00059

11. Yang Y. Cancer Immunotherapy: Harnessing the Immune System to Battle Cancer. J Clin Invest (2015) 125(9):3335-7. doi: 10.1172/JCI83871

12. Filley AC, Henriquez M, Dey M. CART Immunotherapy: Development, Success, and Translation to Malignant Gliomas and Other Solid Tumors. Front Oncol (2018) 8:453. doi: 10.3389/fonc.2018.00453

13. Bilusic M, Madan RA, Gulley JL. Immunotherapy of Prostate Cancer: Facts and Hopes. Clin Cancer Res (2017) 23(22):6764-70. doi: 10.1158/1078-0432.CCR-17-0019

14. Geletneky K, Kiprianova I, Ayache A, Koch R, Herrero YCM, Deleu L, et al. Regression of Advanced Rat and Human Gliomas by Local or Systemic Treatment With Oncolytic Parvovirus H-1 in Rat Models. Neuro Oncol (2010) 12(8):804-14. doi: 10.1093/neuonc/noq023

15. Samson A, Scott KJ, Taggart D, West EJ, Wilson E, Nuovo GJ, et al. Intravenous Delivery of Oncolytic Reovirus to Brain Tumor Patients Immunologically Primes for Subsequent Checkpoint Blockade. Sci Transl Med (2018) 10(422):eaam7577. doi: 10.1126/scitranslmed.aam7577

16. Miyauchi JT, Tsirka SE. Advances in Immunotherapeutic Research for Glioma Therapy. J Neurol (2018) 265(4):741-56. doi: 10.1007/s00415-017-8695-5

17. Schlager C, Korner H, Krueger M, Vidoli S, Haberl M, Mielke D, et al. Effector T-Cell Trafficking Between the Leptomeninges and the
Basic and Applied Basic Research Foundation (grant number 2019A1515011564) and Pearl River S\&T Nova Program of Guangzhou (grant number 201906010069).

\section{ACKNOWLEDGMENTS}

We thank Doctor Roy Gaurab for offering help in reviewing and revising the manuscript.

Cerebrospinal Fluid. Nature (2016) 530(7590):349-53. doi: 10.1038/ nature 16939

18. Sampson JH, Gunn MD, Fecci PE, Ashley DM. Brain Immunology and Immunotherapy in Brain Tumours. Nat Rev Cancer (2020) 20(1):12-25. doi: 10.1038/s41568-019-0224-7

19. Ajami B, Bennett JL, Krieger C, McNagny KM, Rossi FM. Infiltrating Monocytes Trigger EAE Progression, But do Not Contribute to the Resident Microglia Pool. Nat Neurosci (2011) 14(9):1142-9. doi: 10.1038/nn.2887

20. Monier A, Adle-Biassette H, Delezoide AL, Evrard P, Gressens P, Verney C. Entry and Distribution of Microglial Cells in Human Embryonic and Fetal Cerebral Cortex. J Neuropathol Exp Neurol (2007) 66(5):372-82. doi: 10.1097/nen.0b013e3180517b46

21. Wang C, Yue H, Hu Z, Shen Y, Ma J, Li J, et al. Microglia Mediate Forgetting via Complement-Dependent Synaptic Elimination. Science (2020) 367 (6478):688-94. doi: 10.1126/science.aaz2288

22. Shi Q, Chowdhury S, Ma R, Le KX, Hong S, Caldarone BJ, et al. Complement C3 Deficiency Protects Against Neurodegeneration in Aged Plaque-Rich APP/PS1 Mice. Sci Transl Med (2017) 9(392):eaaf6295. doi: 10.1126/ scitranslmed.aaf6295

23. Hambardzumyan D, Gutmann DH, Kettenmann H. The Role of Microglia and Macrophages in Glioma Maintenance and Progression. Nat Neurosci (2016) 19(1):20-7. doi: 10.1038/nn.4185

24. Markovic DS, Glass R, Synowitz M, Rooijen N, Kettenmann H. Microglia Stimulate the Invasiveness of Glioma Cells by Increasing the Activity of Metalloprotease-2. J Neuropathol Exp Neurol (2005) 64(9):754-62. doi: 10.1097/01.jnen.0000178445.33972.a9

25. Shen X, Burguillos MA, Osman AM, Frijhoff J, Carrillo-Jimenez A, Kanatani $\mathrm{S}$, et al. Glioma-Induced Inhibition of Caspase-3 in Microglia Promotes a Tumor-Supportive Phenotype. Nat Immunol (2016) 17(11):1282-90. doi: 10.1038/ni.3545

26. Zhang J, Sarkar S, Cua R, Zhou Y, Hader W, Yong VW, et al. and Microglia That Promotes Tumor Invasiveness Through the CCL2/CCR2/interleukin-6 Axis. Carcinogenesis (2012) 33(2):312-9. doi: 10.1093/carcin/bgr289

27. Chang AL, Miska J, Wainwright DA, Dey M, Rivetta CV, Yu D, et al. CCL2 Produced by the Glioma Microenvironment Is Essential for the Recruitment of Regulatory T Cells and Myeloid-Derived Suppressor Cells. Cancer Res (2016) 76(19):5671-82. doi: 10.1158/0008-5472.CAN-16-0144

28. Pyonteck SM, Akkari L, Schuhmacher AJ, Bowman RL, Sevenich L, Quail DF, et al. CSF-1R Inhibition Alters Macrophage Polarization and Blocks Glioma Progression. Nat Med (2013) 19(10):1264-72. doi: 10.1038/nm.3337

29. Zhu C, Kros JM, Cheng C, Mustafa D. The Contribution of TumorAssociated Macrophages in Glioma Neo-Angiogenesis and Implications for Anti-Angiogenic Strategies. Neuro Oncol (2017) 19(11):1435-46. doi: 10.1093/neuonc/nox081

30. Akkari L, Bowman RL, Tessier J, Klemm F, Handgraaf SM, de Groot M, et al. Dynamic Changes in Glioma Macrophage Populations After Radiotherapy Reveal CSF-1R Inhibition as a Strategy to Overcome Resistance. Sci Transl Med (2020) 12(552):eaaw7843. doi: 10.1126/scitranslmed.aaw7843

31. Poon CC, Sarkar S, Yong VW, Kelly JJP. Glioblastoma-Associated Microglia and Macrophages: Targets for Therapies to Improve Prognosis. Brain (2017) 140(6):1548-60. doi: 10.1093/brain/aww355

32. Wolburg H, Noell S, Fallier-Becker P, Mack AF, Wolburg-Buchholz K. The Disturbed Blood-Brain Barrier in Human Glioblastoma. Mol Aspects Med (2012) 33(5-6):579-89. doi: 10.1016/j.mam.2012.02.003 
33. Schneider SW, Ludwig T, Tatenhorst L, Braune S, Oberleithner H, Senner V, et al. Glioblastoma Cells Release Factors That Disrupt Blood-Brain Barrier Features. Acta Neuropathol (2004) 107(3):272-6. doi: 10.1007/s00401-003-0810-2

34. Chongsathidkiet P, Jackson C, Koyama S, Loebel F, Cui X, Farber SH, et al. Sequestration of T Cells in Bone Marrow in the Setting of Glioblastoma and Other Intracranial Tumors. Nat Med (2018) 24(9):1459-68. doi: 10.1038/ s41591-018-0135-2

35. Schwab SR, Pereira JP, Matloubian M, Xu Y, Huang Y, Cyster JG. Lymphocyte Sequestration Through S1P Lyase Inhibition and Disruption of S1P Gradients. Science (2005) 309(5741):1735-9. doi: 10.1126/ science. 1113640

36. Perng P, Lim M. Immunosuppressive Mechanisms of Malignant Gliomas: Parallels at Non-CNS Sites. Front Oncol (2015) 5:153. doi: 10.3389/ fonc. 2015.00153

37. Vitkovic L, Maeda S, Sternberg E. Anti-Inflammatory Cytokines: Expression and Action in the Brain. Neuroimmunomodulation (2001) 9(6):295-312. doi: $10.1159 / 000059387$

38. Gong D, Shi W, Yi SJ, Chen H, Groffen J, Heisterkamp N. TGFbeta Signaling Plays a Critical Role in Promoting Alternative Macrophage Activation. BMC Immunol (2012) 13:31. doi: 10.1186/1471-2172-13-31

39. Wainwright DA, Balyasnikova IV, Chang AL, Ahmed AU, Moon KS, Auffinger B, et al. IDO Expression in Brain Tumors Increases the Recruitment of Regulatory T Cells and Negatively Impacts Survival. Clin Cancer Res (2012) 18(22):6110-21. doi: 10.1158/1078-0432.CCR-12-2130

40. Zhang I, Alizadeh D, Liang J, Zhang L, Gao H, Song Y, et al. Characterization of Arginase Expression in Glioma-Associated Microglia and Macrophages. PloS One (2016) 11(12):e0165118. doi: 10.1371/journal.pone.0165118

41. Miret JJ, Kirschmeier P, Koyama S, Zhu M, Li YY, Naito Y, et al. Suppression of Myeloid Cell Arginase Activity Leads to Therapeutic Response in a NSCLC Mouse Model by Activating Anti-Tumor Immunity. J Immunother Cancer (2019) 7(1):32. doi: 10.1186/s40425-019-0504-5

42. Wang Z, Zhang C, Liu X, Wang Z, Sun L, Li G, et al. Molecular and Clinical Characterization of PD-L1 Expression at Transcriptional Level via 976 Samples of Brain Glioma. Oncoimmunology (2016) 5(11):e1196310. doi: 10.1080/2162402X.2016.1196310

43. Andtbacka RH, Kaufman HL, Collichio F, Amatruda T, Senzer N, Chesney J, et al. Talimogene Laherparepvec Improves Durable Response Rate in Patients With Advanced Melanoma. J Clin Oncol (2015) 33(25):2780-8. doi: 10.1200/JCO.2014.58.3377

44. Foreman PM, Friedman GK, Cassady KA, Markert JM. Oncolytic Virotherapy for the Treatment of Malignant Glioma. Neurotherapeutics (2017) 14(2):333-44. doi: 10.1007/s13311-017-0516-0

45. Adair RA, Roulstone V, Scott KJ, Morgan R, Nuovo GJ, Fuller M, et al. Cell Carriage, Delivery, and Selective Replication of an Oncolytic Virus in Tumor in Patients. Sci Transl Med (2012) 4(138):138ra77. doi: 10.1126/ scitranslmed. 3003578

46. Stojdl DF, Lichty B, Knowles S, Marius R, Atkins H, Sonenberg N, et al. Exploiting Tumor-Specific Defects in the Interferon Pathway With a Previously Unknown Oncolytic Virus. Nat Med (2000) 6(7):821-5. doi: $10.1038 / 77558$

47. Shi T, Song X, Wang Y, Liu F, Wei J. Combining Oncolytic Viruses With Cancer Immunotherapy: Establishing a New Generation of Cancer Treatment. Front Immunol (2020) 11:683. doi: 10.3389/fimmu.2020.00683

48. Saha D, Wakimoto H, Rabkin SD. Oncolytic Herpes Simplex Virus Interactions With the Host Immune System. Curr Opin Virol (2016) 21:26-34. doi: 10.1016/j.coviro.2016.07.007

49. Kanerva A, Nokisalmi P, Diaconu I, Koski A, Cerullo V, Liikanen I, et al. Antiviral and Antitumor T-Cell Immunity in Patients Treated With GMCSF-Coding Oncolytic Adenovirus. Clin Cancer Res (2013) 19(10):2734-44. doi: 10.1158/1078-0432.CCR-12-2546

50. Cai J, Lin Y, Zhang H, Liang J, Tan Y, Cavenee WK, et al. Selective Replication of Oncolytic Virus M1 Results in a Bystander Killing Effect That is Potentiated by Smac Mimetics. Proc Natl Acad Sci USA (2017) 114 (26):6812-7. doi: 10.1073/pnas.1701002114

51. Loya SM, Zhang X. Enhancing the Bystander Killing Effect of an Oncolytic HSV by Arming it With a Secretable Apoptosis Activator. Gene Ther (2015) 22(3):237-46. doi: 10.1038/gt.2014.113
52. Gujar S, Pol JG, Kroemer G. Heating it Up: Oncolytic Viruses Make Tumors 'Hot' and Suitable for Checkpoint Blockade Immunotherapies. Oncoimmunology (2018) 7(8):e1442169. doi: 10.1080/2162402X.2018.1442169

53. Alvarado AG, Thiagarajan PS, Mulkearns-Hubert EE, Silver DJ, Hale JS, Alban TJ, et al. Glioblastoma Cancer Stem Cells Evade Innate Immune Suppression of Self-Renewal Through Reduced TLR4 Expression. Cell Stem Cell (2017) 20(4):450-61.e4. doi: 10.1016/j.stem.2016.12.001

54. Zhan X, Guo S, Li Y, Ran H, Huang H, Mi L, et al. Glioma Stem-Like Cells Evade Interferon Suppression Through MBD3/NuRD Complex-Mediated STAT1 Downregulation. J Exp Med (2020) 217(5):e20191340. doi: 10.1084/ jem.20191340

55. Maxwell R, Luksik AS, Garzon-Muvdi T, Lim M. The Potential of Cellularand Viral-Based Immunotherapies for Malignant Glioma-Dendritic Cell Vaccines, Adoptive Cell Transfer, and Oncolytic Viruses. Curr Neurol Neurosci Rep (2017) 17(6):50. doi: 10.1007/s11910-017-0754-x

56. Wollmann G, Ozduman K, van den Pol AN. Oncolytic Virus Therapy for Glioblastoma Multiforme: Concepts and Candidates. Cancer J (2012) 18 (1):69-81. doi: 10.1097/PPO.0b013e31824671c9

57. Jiang H, Clise-Dwyer K, Ruisaard KE, Fan X, Tian W, Gumin J, et al. Delta24-RGD Oncolytic Adenovirus Elicits Anti-Glioma Immunity in an Immunocompetent Mouse Model. PloS One (2014) 9(5):e97407. doi: 10.1371/journal.pone. 0097407

58. Koks CA, Garg AD, Ehrhardt M, Riva M, Vandenberk L, Boon L, et al. Newcastle Disease Virotherapy Induces Long-Term Survival and TumorSpecific Immune Memory in Orthotopic Glioma Through the Induction of Immunogenic Cell Death. Int J Cancer (2015) 136(5):E313-25. doi: 10.1002/ ijc.29202

59. Lang FF, Conrad C, Gomez-Manzano C, Yung WKA, Sawaya R, Weinberg JS, et al. Phase I Study of DNX-2401 (Delta-24-RGD) Oncolytic Adenovirus: Replication and Immunotherapeutic Effects in Recurrent Malignant Glioma. J Clin Oncol (2018) 36(14):1419-27. doi: 10.1200/JCO.2017.75.8219

60. Angelova AL, Barf M, Geletneky K, Unterberg A, Rommelaere J. Immunotherapeutic Potential of Oncolytic H-1 Parvovirus: Hints of Glioblastoma Microenvironment Conversion Towards Immunogenicity. Viruses (2017) 9(12):382. doi: 10.3390/v9120382

61. Martikainen M, Essand M. Virus-Based Immunotherapy of Glioblastoma. Cancers (Basel) (2019) 11(2):186. doi: 10.3390/cancers11020186

62. Zhang H, Lin Y, Li K, Liang J, Xiao X, Cai J, et al. Naturally Existing Oncolytic Virus M1 Is Nonpathogenic for the Nonhuman Primates After Multiple Rounds of Repeated Intravenous Injections. Hum Gene Ther (2016) 27(9):700-11. doi: 10.1089/hum.2016.038

63. Farassati F, Yang AD, Lee PW. Oncogenes in Ras Signalling Pathway Dictate Host-Cell Permissiveness to Herpes Simplex Virus 1. Nat Cell Biol (2001) 3 (8):745-50. doi: 10.1038/35087061

64. Chou J, Kern ER, Whitley RJ, Roizman B. Mapping of Herpes Simplex Virus-1 Neurovirulence to Gamma 134.5, a Gene Nonessential for Growth in Culture. Science (1990) 250(4985):1262-6. doi: 10.1126/science.2173860

65. MacLean AR, ul-Fareed M, Robertson L, Harland J, Brown SM. Herpes Simplex Virus Type 1 Deletion Variants 1714 and 1716 Pinpoint Neurovirulence-Related Sequences in Glasgow Strain 17+ Between Immediate Early Gene 1 and the 'A' Sequence. J Gen Virol (1991) 72(Pt 3):631-9. doi: 10.1099/0022-1317-72-3-631

66. Gromeier M, Alexander L, Wimmer E. Internal Ribosomal Entry Site Substitution Eliminates Neurovirulence in Intergeneric Poliovirus Recombinants. Proc Natl Acad Sci USA (1996) 93(6):2370-5. doi: 10.1073/ pnas.93.6.2370

67. van den Pol AN, Dalton KP, Rose JK. Relative Neurotropism of a Recombinant Rhabdovirus Expressing a Green Fluorescent Envelope Glycoprotein. J Virol (2002) 76(3):1309-27. doi: 10.1128/jvi.76.3.13091327.2002

68. Wollmann G, Rogulin V, Simon I, Rose JK, van den Pol AN. Some Attenuated Variants of Vesicular Stomatitis Virus Show Enhanced Oncolytic Activity Against Human Glioblastoma Cells Relative to Normal Brain Cells. J Virol (2010) 84(3):1563-73. doi: 10.1128/JVI.02040-09

69. Abudoureyimu M, Lai Y, Tian C, Wang T, Wang R, Chu X. Oncolytic Adenovirus-A Nova for Gene-Targeted Oncolytic Viral Therapy in HCC. Front Oncol (2019) 9:1182. doi: 10.3389/fonc.2019.01182 
70. Kaufman HL, Kohlhapp FJ, Zloza A. Oncolytic Viruses: A New Class of Immunotherapy Drugs. Nat Rev Drug Discov (2016) 15(9):660. doi: 10.1038/ $\operatorname{nrd} .2016 .178$

71. Advani SJ, Markert JM, Sood RF, Samuel S, Gillespie GY, Shao MY, et al. Increased Oncolytic Efficacy for High-Grade Gliomas by Optimal Integration of Ionizing Radiation Into the Replicative Cycle of HSV-1. Gene Ther (2011) 18(11):1098-102. doi: 10.1038/gt.2011.61

72. Marchini A, Bonifati S, Scott EM, Angelova AL, Rommelaere J. Oncolytic Parvoviruses: From Basic Virology to Clinical Applications. Virol J (2015) 12:6. doi: 10.1186/s12985-014-0223-y

73. Guo ZS, Lu B, Guo Z, Giehl E, Feist M, Dai E, et al. Vaccinia Virus-Mediated Cancer Immunotherapy: Cancer Vaccines and Oncolytics. I Immunother Cancer (2019) 7(1):6. doi: 10.1186/s40425-018-0495-7

74. Bommareddy PK, Shettigar M, Kaufman HL. Integrating Oncolytic Viruses in Combination Cancer Immunotherapy. Nat Rev Immunol (2018) 18 (8):498-513. doi: 10.1038/s41577-018-0014-6

75. Rahman MM, McFadden G. Oncolytic Virotherapy With Myxoma Virus. J Clin Med (2020) 9(1):171. doi: 10.3390/jcm9010171

76. Ilett EJ, Prestwich RJ, Kottke T, Errington F, Thompson JM, Harrington KJ, et al. Dendritic Cells and T Cells Deliver Oncolytic Reovirus for Tumour Killing Despite Pre-Existing Anti-Viral Immunity. Gene Ther (2009) 16 (5):689-99. doi: 10.1038/gt.2009.29

77. Korotkova EA, Prostova MA, Gmyl AP, Kozlovskaya LI, Eremeeva TP, Baikova OY, et al. Case of Poliomyelitis Caused by Significantly Diverged Derivative of the Poliovirus Type 3 Vaccine Sabin Strain Circulating in the Orphanage. Viruses (2020) 12(9):970. doi: 10.3390/v12090970

78. Hsu EC, Sarangi F, Iorio C, Sidhu MS, Udem SA, Dillehay DL, et al. A Single Amino Acid Change in the Hemagglutinin Protein of Measles Virus Determines its Ability to Bind CD46 and Reveals Another Receptor on Marmoset B Cells. J Virol (1998) 72(4):2905-16. doi: 10.1128/JVI.72.4.2905-2916.1998

79. Lundstrom K. RNA Viruses as Tools in Gene Therapy and Vaccine Development. Genes (Basel) (2019) 10(3):189. doi: 10.3390/genes10030189

80. Burman B, Pesci G, Zamarin D. Newcastle Disease Virus at the Forefront of Cancer Immunotherapy. Cancers (Basel) (2020) 12(12):3552. doi: 10.3390/cancers12123552

81. Patil G, Xu L, Wu Y, Song K, Hao W, Hua F, et al. TRIM41-Mediated Ubiquitination of Nucleoprotein Limits Vesicular Stomatitis Virus Infection. Viruses (2020) 12(2):131. doi: 10.3390/v12020131

82. Nermut MV, Hockley DJ. Comparative Morphology and Structural Classification of Retroviruses. Curr Top Microbiol Immunol (1996) 214:124. doi: 10.1007/978-3-642-80145-7_1

83. Faye O, Freire CC, Iamarino A, Faye O, de Oliveira JV, Diallo M, et al. Molecular Evolution of Zika Virus During its Emergence in the 20(Th) Century. PloS Negl Trop Dis (2014) 8(1):e2636. doi: 10.1371/journal.pntd.0002636

84. To A, Medina LO, Mfuh KO, Lieberman MM, Wong TAS, Namekar M, et al. Recombinant Zika Virus Subunits Are Immunogenic and Efficacious in Mice. mSphere (2018) 3(1):e00576-17. doi: 10.1128/mSphere.00576-17

85. Wen JS, Zhao WZ, Liu JW, Zhou H, Tao JP, Yan HJ, et al. Genomic Analysis of a Chinese Isolate of Getah-Like Virus and Its Phylogenetic Relationship With Other Alphaviruses. Virus Genes (2007) 35(3):597-603. doi: 10.1007/ s11262-007-0110-3

86. Lundstrom K. Oncolytic Alphaviruses in Cancer Immunotherapy. Vaccines (Basel) (2017) 5(2):9. doi: 10.3390/vaccines5020009

87. Burke MJ. Oncolytic Seneca Valley Virus: Past Perspectives and Future Directions. Oncolytic Virother (2016) 5:81-9. doi: 10.2147/OV.S96915

88. Huang H, Liu Y, Liao W, Cao Y, Liu Q, Guo Y, et al. Oncolytic Adenovirus Programmed by Synthetic Gene Circuit for Cancer Immunotherapy. Nat Commun (2019) 10(1):4801. doi: 10.1038/s41467-019-12794-2

89. Philbrick B, Adamson DC. DNX-2401: An Investigational Drug for the Treatment of Recurrent Glioblastoma. Expert Opin Investig Drugs (2019) 28 (12):1041-9. doi: 10.1080/13543784.2019.1694000

90. Jiang H, Gomez-Manzano C, Aoki H, Alonso MM, Kondo S, McCormick F, et al. Examination of the Therapeutic Potential of Delta-24-RGD in Brain Tumor Stem Cells: Role of Autophagic Cell Death. J Natl Cancer Inst (2007) 99(18):1410-4. doi: 10.1093/jnci/djm102

91. van Putten EH, Wembacher-Schroder E, Smits M, Dirven CM. Magnetic Resonance Imaging-Based Assessment of Gadolinium-Conjugated Diethylenetriamine Penta-Acetic Acid Test-Infusion in Detecting
Dysfunction of Convection-Enhanced Delivery Catheters. World Neurosurg (2016) 89:272-9. doi: 10.1016/j.wneu.2016.02.003

92. Vogelbaum MA, Aghi MK. Convection-Enhanced Delivery for the Treatment of Glioblastoma. Neuro Oncol (2015) 17:ii3-8. doi: 10.1093/ neuonc/nou354

93. Kim JW, Auffinger B, Spencer DA, Miska J, Chang AL, Kane JR, et al. Single Dose GLP Toxicity and Biodistribution Study of a Conditionally Replicative Adenovirus Vector, CRAd-S-Pk7, Administered by Intracerebral Injection to Syrian Hamsters. J Transl Med (2016) 14(1):134. doi: 10.1186/s12967016-0895-8

94. Chastkofsky MI, Pituch KC, Katagi H, Zannikou M, Ilut L, Xiao T, et al. Mesenchymal Stem Cells Successfully Deliver Oncolytic Virotherapy to Diffuse Intrinsic Pontine Glioma. Clin Cancer Res (2021) 27(6):1766-77. doi: 10.1158/1078-0432.CCR-20-1499

95. Taipale K, Liikanen I, Juhila J, Turkki R, Tahtinen S, Kankainen M, et al. Chronic Activation of Innate Immunity Correlates With Poor Prognosis in Cancer Patients Treated With Oncolytic Adenovirus. Mol Ther (2016) 24 (1):175-83. doi: $10.1038 / \mathrm{mt} .2015 .143$

96. Marelli G, Howells A, Lemoine NR, Wang Y. Oncolytic Viral Therapy and the Immune System: A Double-Edged Sword Against Cancer. Front Immunol (2018) 9:866. doi: 10.3389/fimmu.2018.00866

97. Todo T. Active Immunotherapy: Oncolytic Virus Therapy Using HSV-1. Adv Exp Med Biol (2012) 746:178-86. doi: 10.1007/978-1-4614-3146-6_14

98. Cheema TA, Wakimoto H, Fecci PE, Ning J, Kuroda T, Jeyaretna DS, et al. Multifaceted Oncolytic Virus Therapy for Glioblastoma in an Immunocompetent Cancer Stem Cell Model. Proc Natl Acad Sci USA (2013) 110(29):12006-11. doi: 10.1073/pnas.1307935110

99. Gutzmer R, Harrington KJ, Hoeller C, Lebbe C, Malvehy J, Ohrling K, et al. Practical Clinical Guide on the Use of Talimogene Laherparepvec Monotherapy in Patients With Unresectable Melanoma in Europe. Eur J Dermatol (2018) 28(6):736-49. doi: 10.1684/ejd.2018.3447

100. Markert JM, Medlock MD, Rabkin SD, Gillespie GY, Todo T, Hunter WD, et al. Conditionally Replicating Herpes Simplex Virus Mutant, G207 for the Treatment of Malignant Glioma: Results of a Phase I Trial. Gene Ther (2000) 7(10):867-74. doi: 10.1038/sj.gt.3301205

101. Rampling R, Cruickshank G, Papanastassiou V, Nicoll J, Hadley D, Brennan D, et al. Toxicity Evaluation of Replication-Competent Herpes Simplex Virus (ICP 34.5 Null Mutant 1716) in Patients With Recurrent Malignant Glioma. Gene Ther (2000) 7(10):859-66. doi: 10.1038/sj.gt.3301184

102. Markert JM, Razdan SN, Kuo HC, Cantor A, Knoll A, Karrasch M, et al. A Phase 1 Trial of Oncolytic HSV-1, G207, Given in Combination With Radiation for Recurrent GBM Demonstrates Safety and Radiographic Responses. Mol Ther (2014) 22(5):1048-55. doi: 10.1038/mt.2014.22

103. Friedman GK, Johnston JM, Bag AK, Bernstock JD, Li R, Aban I, et al. Oncolytic HSV-1 G207 Immunovirotherapy for Pediatric High-Grade Gliomas. N Engl J Med (2021) 384(17):1613-22. doi: 10.1056/NEJMoa2024947

104. Sugawara K, Iwai M, Yajima S, Tanaka M, Yanagihara K, Seto Y, et al. Efficacy of a Third-Generation Oncolytic Herpes Virus G47Delta in Advanced Stage Models of Human Gastric Cancer. Mol Ther Oncolytics (2020) 17:205-15. doi: 10.1016/j.omto.2020.03.022

105. Fukuhara H, Ino Y, Todo T. Oncolytic Virus Therapy: A New Era of Cancer Treatment at Dawn. Cancer Sci (2016) 107(10):1373-9. doi: 10.1111/ cas. 13027

106. Taguchi S, Fukuhara H, Todo T. Oncolytic Virus Therapy in Japan: Progress in Clinical Trials and Future Perspectives. Jpn J Clin Oncol (2019) 49(3):2019. doi: 10.1093/jjco/hyy170

107. Angelova AL, Geletneky K, Nuesch JP, Rommelaere J. Tumor Selectivity of Oncolytic Parvoviruses: From In Vitro and Animal Models to Cancer Patients. Front Bioeng Biotechnol (2015) 3:55. doi: 10.3389/fbioe.2015.00055

108. Geletneky K, Nuesch JP, Angelova A, Kiprianova I, Rommelaere J. DoubleFaceted Mechanism of Parvoviral Oncosuppression. Curr Opin Virol (2015) 13:17-24. doi: 10.1016/j.coviro.2015.03.008

109. Moehler MH, Zeidler M, Wilsberg V, Cornelis JJ, Woelfel T, Rommelaere J, et al. Parvovirus H-1-Induced Tumor Cell Death Enhances Human Immune Response In Vitro via Increased Phagocytosis, Maturation, and CrossPresentation by Dendritic Cells. Hum Gene Ther (2005) 16(8):996-1005. doi: 10.1089/hum.2005.16.996 
110. Geletneky K, Hajda J, Angelova AL, Leuchs B, Capper D, Bartsch AJ, et al. Oncolytic H-1 Parvovirus Shows Safety and Signs of Immunogenic Activity in a First Phase I/IIa Glioblastoma Trial. Mol Ther (2017) 25(12):2620-34. doi: 10.1016/j.ymthe.2017.08.016

111. Jiang B, Lun X, Hao X, Wang Y, Yin X, Huang D, et al. Temozolomide Resistant Human Brain Tumor Stem Cells are Susceptible to Recombinant Vesicular Stomatitis Virus and Double-Deleted Vaccinia Virus In Vitro. BioMed Pharmacother (2017) 95:1201-8. doi: 10.1016/j.biopha.2017.09.030

112. Lun X, Ruan Y, Jayanthan A, Liu DJ, Singh A, Trippett T, et al. Double-Deleted Vaccinia Virus in Virotherapy for Refractory and Metastatic Pediatric Solid Tumors. Mol Oncol (2013) 7(5):944-54. doi: 10.1016/j.molonc.2013.05.004

113. Tang B, Guo ZS, Bartlett DL, Yan DZ, Schane CP, Thomas DL, et al. Synergistic Combination of Oncolytic Virotherapy and Immunotherapy for Glioma. Clin Cancer Res (2020) 26(9):2216-30. doi: 10.1158/1078-0432.CCR-18-3626

114. Lun X, Yang W, Alain T, Shi ZQ, Muzik H, Barrett JW, et al. Myxoma Virus is a Novel Oncolytic Virus With Significant Antitumor Activity Against Experimental Human Gliomas. Cancer Res (2005) 65(21):9982-90. doi: 10.1158/0008-5472.CAN-05-1201

115. Lun X, Alain T, Zemp FJ, Zhou H, Rahman MM, Hamilton MG, et al. Myxoma Virus Virotherapy for Glioma in Immunocompetent Animal Models: Optimizing Administration Routes and Synergy With Rapamycin. Cancer Res (2010) 70(2):598-608. doi: 10.1158/0008-5472.CAN-09-1510

116. Ogbomo H, Zemp FJ, Lun X, Zhang J, Stack D, Rahman MM, et al. Myxoma Virus Infection Promotes NK Lysis of Malignant Gliomas In Vitro and In Vivo. PloS One (2013) 8(6):e66825. doi: 10.1371/journal.pone.0066825

117. Zemp FJ, Lun X, McKenzie BA, Zhou H, Maxwell L, Sun B, et al. Treating Brain Tumor-Initiating Cells Using a Combination of Myxoma Virus and Rapamycin. Neuro Oncol (2013) 15(7):904-20. doi: 10.1093/neuonc/not035

118. Pisklakova A, McKenzie B, Zemp F, Lun X, Kenchappa RS, Etame AB, et al. M011L-Deficient Oncolytic Myxoma Virus Induces Apoptosis in Brain Tumor-Initiating Cells and Enhances Survival in a Novel Immunocompetent Mouse Model of Glioblastoma. Neuro Oncol (2016) 18(8):1088-98. doi: 10.1093/neuonc/now006

119. McKenzie BA, Zemp FJ, Pisklakova A, Narendran A, McFadden G, Lun X, et al. In Vitro Screen of a Small Molecule Inhibitor Drug Library Identifies Multiple Compounds That Synergize With Oncolytic Myxoma Virus Against Human Brain Tumor-Initiating Cells. Neuro Oncol (2015) 17 (8):1086-94. doi: 10.1093/neuonc/nou359

120. Tang B, Guo ZS, Bartlett DL, Yan DZ, Schane CP, Thomas DL, et al. Synergistic Combination of Oncolytic Virotherapy and Immunotherapy for Glioma. Clin Cancer Res (2020) 26(9):2216-30. doi: 10.1158/10780432.CCR-18-3626

121. Wilcox ME, Yang W, Senger D, Rewcastle NB, Morris DG, Brasher PM, et al. Reovirus as an Oncolytic Agent Against Experimental Human Malignant Gliomas. J Natl Cancer Inst (2001) 93(12):903-12. doi: 10.1093/jnci/93.12.903

122. Forsyth P, Roldan G, George D, Wallace C, Palmer CA, Morris D, et al. A Phase I Trial of Intratumoral Administration of Reovirus in Patients With Histologically Confirmed Recurrent Malignant Gliomas. Mol Ther (2008) 16 (3):627-32. doi: 10.1038/sj.mt.6300403

123. Kicielinski KP, Chiocca EA, Yu JS, Gill GM, Coffey M, Markert JM. Phase 1 Clinical Trial of Intratumoral Reovirus Infusion for the Treatment of Recurrent Malignant Gliomas in Adults. Mol Ther (2014) 22(5):1056-62. doi: $10.1038 / \mathrm{mt} .2014 .21$

124. Jaime-Ramirez AC, Yu JG, Caserta E, Yoo JY, Zhang J, Lee TJ, et al. Reolysin and Histone Deacetylase Inhibition in the Treatment of Head and Neck Squamous Cell Carcinoma. Mol Ther Oncolytics (2017) 5:87-96. doi: 10.1016/j.omto.2017.05.002

125. Dobrikova EY, Goetz C, Walters RW, Lawson SK, Peggins JO, Muszynski K, et al. Attenuation of Neurovirulence, Biodistribution, and Shedding of a Poliovirus:Rhinovirus Chimera After Intrathalamic Inoculation in Macaca Fascicularis. J Virol (2012) 86(5):2750-9. doi: 10.1128/JVI.06427-11

126. Goetz C, Dobrikova E, Shveygert M, Dobrikov M, Gromeier M. Oncolytic Poliovirus Against Malignant Glioma. Future Virol (2011) 6(9):1045-58. doi: $10.2217 /$ fvl.11.76

127. Dobrikova EY, Broadt T, Poiley-Nelson J, Yang X, Soman G, Giardina S, et al. Recombinant Oncolytic Poliovirus Eliminates Glioma In Vivo Without
Genetic Adaptation to a Pathogenic Phenotype. Mol Ther (2008) 16 (11):1865-72. doi: $10.1038 / \mathrm{mt} .2008 .184$

128. Gromeier M, Lachmann S, Rosenfeld MR, Gutin PH, Wimmer E. Intergeneric Poliovirus Recombinants for the Treatment of Malignant Glioma. Proc Natl Acad Sci USA (2000) 97(12):6803-8. doi: 10.1073/ pnas.97.12.6803

129. Zhang X, Wang H, Sun Y, Qi M, Li W, Zhang Z, et al. Enterovirus A71 Oncolysis of Malignant Gliomas. Mol Ther (2020) 28(6):1533-46. doi: 10.1016/j.ymthe.2020.04.005

130. Desjardins A, Gromeier M, Herndon JE2nd, Beaubier N, Bolognesi DP, Friedman AH, et al. Recurrent Glioblastoma Treated With Recombinant Poliovirus. N Engl J Med (2018) 379(2):150-61. doi: 10.1056/NEJMoa1716435

131. Anderson BD, Nakamura T, Russell SJ, Peng KW. High CD46 Receptor Density Determines Preferential Killing of Tumor Cells by Oncolytic Measles Virus. Cancer Res (2004) 64(14):4919-26. doi: 10.1158/0008-5472.CAN-040884

132. Myers R, Harvey M, Kaufmann TJ, Greiner SM, Krempski JW, Raffel C, et al. Toxicology Study of Repeat Intracerebral Administration of a Measles Virus Derivative Producing Carcinoembryonic Antigen in Rhesus Macaques in Support of a Phase I/II Clinical Trial for Patients With Recurrent Gliomas. Hum Gene Ther (2008) 19(7):690-8. doi: 10.1089/hum.2008.035

133. Phuong LK, Allen C, Peng KW, Giannini C, Greiner S, TenEyck CJ, et al. Use of a Vaccine Strain of Measles Virus Genetically Engineered to Produce Carcinoembryonic Antigen as a Novel Therapeutic Agent Against Glioblastoma Multiforme. Cancer Res (2003) 63(10):2462-9. doi: 10.1016/ S1525-0016(16)43756-1

134. Hardcastle J, Mills L, Malo CS, Jin F, Kurokawa C, Geekiyanage H, et al. Immunovirotherapy With Measles Virus Strains in Combination With AntiPD-1 Antibody Blockade Enhances Antitumor Activity in Glioblastoma Treatment. Neuro Oncol (2017) 19(4):493-502. doi: 10.1093/neuonc/now179

135. Rajaraman S, Canjuga D, Ghosh M, Codrea MC, Sieger R, Wedekink F, et al. Measles Virus-Based Treatments Trigger a Pro-Inflammatory Cascade and a Distinctive Immunopeptidome in Glioblastoma. Mol Ther Oncolytics (2019) 12:147-61. doi: 10.1016/j.omto.2018.12.010

136. Suryawanshi YR, Schulze AJ. Oncolytic Viruses for Malignant Glioma: On the Verge of Success? Viruses (2021) 13(7):1294. doi: 10.3390/v13071294

137. Aref S, Bailey K, Fielding A. Measles to the Rescue: A Review of Oncolytic Measles Virus. Viruses (2016) 8(10):294. doi: 10.3390/v8100294

138. Myers RM, Greiner SM, Harvey ME, Griesmann G, Kuffel MJ, Buhrow SA, et al. Preclinical Pharmacology and Toxicology of Intravenous MV-NIS, an Oncolytic Measles Virus Administered With or Without Cyclophosphamide. Clin Pharmacol Ther (2007) 82(6):700-10. doi: 10.1038/sj.clpt.6100409

139. Zulkifli MM, Ibrahim R, Ali AM, Aini I, Jaafar H, Hilda SS, et al. Newcastle Diseases Virus Strain V4UPM Displayed Oncolytic Ability Against Experimental Human Malignant Glioma. Neurol Res (2009) 31(1):3-10. doi: $10.1179 / 174313208 X 325218$

140. Schirrmacher V, van Gool S, Stuecker W. Breaking Therapy Resistance: An Update on Oncolytic Newcastle Disease Virus for Improvements of Cancer Therapy. Biomedicines (2019) 7(3):66. doi: 10.3390/biomedicines7030066

141. Fan X, Lu H, Cui Y, Hou X, Huang C, Liu G. Overexpression of P53 Delivered Using Recombinant NDV Induces Apoptosis in Glioma Cells by Regulating the Apoptotic Signaling Pathway. Exp Ther Med (2018) 15 (5):4522-30. doi: 10.3892/etm.2018.5935

142. Freeman AI, Zakay-Rones Z, Gomori JM, Linetsky E, Rasooly L, Greenbaum E, et al. Phase I/II Trial of Intravenous NDV-HUJ Oncolytic Virus in Recurrent Glioblastoma Multiforme. Mol Ther (2006) 13(1):221-8. doi: 10.1016/j.ymthe.2005.08.016

143. Ahmed M, Cramer SD, Lyles DS. Sensitivity of Prostate Tumors to Wild Type and M Protein Mutant Vesicular Stomatitis Viruses. Virology (2004) 330(1):34-49. doi: 10.1016/j.virol.2004.08.039

144. Hastie E, Grdzelishvili VZ. Vesicular Stomatitis Virus as a Flexible Platform for Oncolytic Virotherapy Against Cancer. J Gen Virol (2012) 93(Pt 12):2529-45. doi: 10.1099/vir.0.046672-0

145. Zhang X, Mao G, van den Pol AN. Chikungunya-Vesicular Stomatitis Chimeric Virus Targets and Eliminates Brain Tumors. Virology (2018) 522:244-59. doi: 10.1016/j.virol.2018.06.018 
146. Jiang B, Huang D, He W, Guo W, Mm, Yin X, et al. Inhibition of Glioma Using a Novel Non-Neurotoxic Vesicular Stomatitis Virus. Neurosurg Focus (2021) 50(2):E9. doi: 10.3171/2020.11.FOCUS20839

147. Huang TT, Parab S, Burnett R, Diago O, Ostertag D, Hofman FM, et al. Intravenous Administration of Retroviral Replicating Vector, Toca 511, Demonstrates Therapeutic Efficacy in Orthotopic Immune-Competent Mouse Glioma Model. Hum Gene Ther (2015) 26(2):82-93. doi: 10.1089/hum.2014.100

148. Cloughesy TF, Petrecca K, Walbert T, Butowski N, Salacz M, Perry J, et al. Effect of Vocimagene Amiretrorepvec in Combination With Flucytosine vs Standard of Care on Survival Following Tumor Resection in Patients With Recurrent High-Grade Glioma: A Randomized Clinical Trial. JAMA Oncol (2020) 6(12):1939-46. doi: 10.1001/jamaoncol.2020.3161

149. Cloughesy TF, Landolfi J, Vogelbaum MA, Ostertag D, Elder JB, Bloomfield $\mathrm{S}$, et al. Durable Complete Responses in Some Recurrent High-Grade Glioma Patients Treated With Toca 511 + Toca FC. Neuro Oncol (2018) 20 (10):1383-92. doi: 10.1093/neuonc/noy075

150. Huang TT, Hlavaty J, Ostertag D, Espinoza FL, Martin B, Petznek H, et al. Toca 511 Gene Transfer and 5-Fluorocytosine in Combination With Temozolomide Demonstrates Synergistic Therapeutic Efficacy in a Temozolomide-Sensitive Glioblastoma Model. Cancer Gene Ther (2013) 20 (10):544-51. doi: 10.1038/cgt.2013.51

151. Budzik KM, Nace RA, Ikeda Y, Russell SJ. Oncolytic Foamy Virus Generation and Properties of a Nonpathogenic Replicating Retroviral Vector System That Targets Chronically Proliferating Cancer Cells. J Virol (2021) 95(10):e00015-21. doi: 10.1128/JVI.00015-21

152. Hancock WT, Marfel M, Bel M. Zika Virus, French Polynesia, South Pacific, 2013. Emerg Infect Dis (2014) 20(11):1960. doi: 10.3201/eid2011.141380

153. Kuno G, Chang GJ. Full-Length Sequencing and Genomic Characterization of Bagaza, Kedougou, and Zika Viruses. Arch Virol (2007) 152(4):687-96. doi: 10.1007/s00705-006-0903-z

154. Mlakar J, Korva M, Tul N, Popovic M, Poljsak-Prijatelj M, Mraz J, et al. Zika Virus Associated With Microcephaly. N Engl J Med (2016) 374(10):951-8. doi: 10.1056/NEJMoa1600651

155. Papa MP, Meuren LM, Coelho SVA, Lucas CGO, Mustafa YM, Lemos Matassoli F, et al. Zika Virus Infects, Activates, and Crosses Brain Microvascular Endothelial Cells, Without Barrier Disruption. Front Microbiol (2017) 8:2557. doi: 10.3389/fmicb.2017.02557

156. Alimonti JB, Ribecco-Lutkiewicz M, Sodja C, Jezierski A, Stanimirovic DB, Liu Q, et al. Zika Virus Crosses an In Vitro Human Blood Brain Barrier Model. Fluids Barriers CNS (2018) 15(1):15. doi: 10.1186/s12987-018-0100-y

157. Kaid C, Goulart E, Caires-Junior LC, Araujo BHS, Soares-Schanoski A, Bueno HMS, et al. Zika Virus Selectively Kills Aggressive Human Embryonal CNS Tumor Cells In Vitro and In Vivo. Cancer Res (2018) 78(12):3363-74. doi: 10.1158/0008-5472.CAN-17-3201

158. Chen Q, Wu J, Ye Q, Ma F, Zhu Q, Wu Y, et al. Treatment of Human Glioblastoma With a Live Attenuated Zika Virus Vaccine Candidate. mBio (2018) 9(5):e01683-18. doi: 10.1128/mBio.01683-18

159. Nair S, Mazzoccoli L, Jash A, Govero J, Bais SS, Hu T, et al. Zika Virus Oncolytic Activity Requires CD8+ T Cells and is Boosted by Immune Checkpoint Blockade. JCI Insight (2021) 6(1):e144619. doi: 10.1172/ jci.insight.144619

160. Trus I, Berube N, Jiang P, Rak J, Gerdts V, Karniychuk U. Zika Virus With Increased CpG Dinucleotide Frequencies Shows Oncolytic Activity in Glioblastoma Stem Cells. Viruses (2020) 12(5):579. doi: 10.3390/v12050579

161. Kaid C, Madi R, Astray R, Goulart E, Caires-Junior LC, Mitsugi TG, et al. Safety, Tumor Reduction, and Clinical Impact of Zika Virus Injection in Dogs With Advanced-Stage Brain Tumors. Mol Ther (2020) 28(5):1276-86. doi: 10.1016/j.ymthe.2020.03.004

162. Su KY, Balasubramaniam V. Zika Virus as Oncolytic Therapy for Brain Cancer: Myth or Reality? Front Microbiol (2019) 10:2715. doi: 10.3389/ fmicb.2019.02715

163. Lin Y, Zhang H, Liang J, Li K, Zhu W, Fu L, et al. Identification and Characterization of Alphavirus M1 as a Selective Oncolytic Virus Targeting ZAP-Defective Human Cancers. Proc Natl Acad Sci USA (2014) 111(42): E4504-12. doi: 10.1073/pnas.1408759111

164. Li K, Zhang H, Qiu J, Lin Y, Liang J, Xiao X, et al. Activation of Cyclic Adenosine Monophosphate Pathway Increases the Sensitivity of Cancer
Cells to the Oncolytic Virus M1. Mol Ther (2016) 24(1):156-65. doi: $10.1038 / \mathrm{mt} .2015 .172$

165. Hu C, Liu Y, Lin Y, Liang JK, Zhong WW, Li K, et al. Intravenous Injections of the Oncolytic Virus M1 as a Novel Therapy for Muscle-Invasive Bladder Cancer. Cell Death Dis (2018) 9(3):274. doi: 10.1038/s41419-018-0325-3

166. Cai J, Zhu W, Lin Y, Zhang S, Chen X, Gong S, et al. Systematic Characterization of the Biodistribution of the Oncolytic Virus M1. Hum Gene Ther (2020) 23(6):1519-30. doi: 10.1089/hum.2020.114

167. Li K, Hu C, Xing F, Gao M, Liang J, Xiao X, et al. Deficiency of the IRE1alpha-Autophagy Axis Enhances the Antitumor Effects of the Oncolytic Virus M1. J Virol (2018) 92(6):e01331-17. doi: 10.1128/JVI.01331-17

168. Heikkila JE, Vaha-Koskela MJ, Ruotsalainen JJ, Martikainen MW, Stanford MM, McCart JA, et al. Intravenously Administered Alphavirus Vector VA7 Eradicates Orthotopic Human Glioma Xenografts in Nude Mice. PloS One (2010) 5(1):e8603. doi: 10.1371/journal.pone.0008603

169. Ramachandran M, Yu D, Dyczynski M, Baskaran S, Zhang L, Lulla A, et al. Safe and Effective Treatment of Experimental Neuroblastoma and Glioblastoma Using Systemically Delivered Triple MicroRNA-Detargeted Oncolytic Semliki Forest Virus. Clin Cancer Res (2017) 23(6):1519-30. doi: 10.1158/1078-0432.CCR-16-0925

170. Ylosmaki E, Martikainen M, Hinkkanen A, Saksela K. Attenuation of Semliki Forest Virus Neurovirulence by microRNA-Mediated Detargeting. J Virol (2013) 87(1):335-44. doi: 10.1128/JVI.01940-12

171. Martikainen M, Niittykoski M, von und zu Fraunberg M, Immonen A, Koponen S, van Geenen M, et al. MicroRNA-Attenuated Clone of Virulent Semliki Forest Virus Overcomes Antiviral Type I Interferon in Resistant Mouse CT-2a Glioma. J Virol (2015) 89(20):10637-47. doi: 10.1128/ JVI.01868-15

172. Martikainen M, Ramachandran M, Lugano R, Ma J, Martikainen MM, Dimberg A, et al. IFN-I-Tolerant Oncolytic Semliki Forest Virus in Combination With Anti-PD1 Enhances T Cell Response Against Mouse Glioma. Mol Ther Oncolytics (2021) 21:37-46. doi: 10.1016/j.omto.2021. 03.008

173. Liu Z, Zhao X, Mao H, Baxter PA, Huang Y, Yu L, et al. Intravenous Injection of Oncolytic Picornavirus SVV-001 Prolongs Animal Survival in a Panel of Primary Tumor-Based Orthotopic Xenograft Mouse Models of Pediatric Glioma. Neuro Oncol (2013) 15(9):1173-85. doi: 10.1093/neuonc/not065

174. Chen Y, Yu DC, Charlton D, Henderson DR. Pre-Existent Adenovirus Antibody Inhibits Systemic Toxicity and Antitumor Activity of CN706 in the Nude Mouse LNCaP Xenograft Model: Implications and Proposals for Human Therapy. Hum Gene Ther (2000) 11(11):1553-67. doi: 10.1089/ 10430340050083289

175. Niemann J, Woller N, Brooks J, Fleischmann-Mundt B, Martin NT, Kloos A, et al. Molecular Retargeting of Antibodies Converts Immune Defense Against Oncolytic Viruses Into Cancer Immunotherapy. Nat Commun (2019) 10(1):3236. doi: 10.1038/s41467-019-11137-5

176. Ricca JM, Oseledchyk A, Walther T, Liu C, Mangarin L, Merghoub T, et al. PreExisting Immunity to Oncolytic Virus Potentiates Its Immunotherapeutic Efficacy. Mol Ther (2018) 26(4):1008-19. doi: 10.1016/j.ymthe.2018.01.019

177. Tahtinen S, Feola S, Capasso C, Laustio N, Groeneveldt C, Ylosmaki EO, et al. Exploiting Preexisting Immunity to Enhance Oncolytic Cancer Immunotherapy. Cancer Res (2020) 80(12):2575-85. doi: 10.1158/00085472.CAN-19-2062

178. Raja J, Ludwig JM, Gettinger SN, Schalper KA, Kim HS. Oncolytic Virus Immunotherapy: Future Prospects for Oncology. J Immunother Cancer (2018) 6(1):140. doi: 10.1186/s40425-018-0458-z

179. Ong HT, Federspiel MJ, Guo CM, Ooi LL, Russell SJ, Peng KW, et al. Systemically Delivered Measles Virus-Infected Mesenchymal Stem Cells can Evade Host Immunity to Inhibit Liver Cancer Growth. J Hepatol (2013) 59 (5):999-1006. doi: 10.1016/j.jhep.2013.07.010

180. Power AT, Wang J, Falls TJ, Paterson JM, Parato KA, Lichty BD, et al. Carrier Cell-Based Delivery of an Oncolytic Virus Circumvents Antiviral Immunity. Mol Ther (2007) 15(1):123-30. doi: 10.1038/sj.mt.6300039

181. Ohkuri T, Ghosh A, Kosaka A, Zhu J, Ikeura M, David M, et al. STING Contributes to Antiglioma Immunity via Triggering Type I IFN Signals in the Tumor Microenvironment. Cancer Immunol Res (2014) 2(12):1199-208. doi: 10.1158/2326-6066.CIR-14-0099 
182. Fujita M, Scheurer ME, Decker SA, McDonald HA, Kohanbash G, Kastenhuber ER, et al. Role of Type 1 IFNs in Antiglioma Immunosurveillance-Using Mouse Studies to Guide Examination of Novel Prognostic Markers in Humans. Clin Cancer Res (2010) 16(13):3409-19. doi: 10.1158/1078-0432.CCR-10-0644

183. Zitvogel L, Galluzzi L, Kepp O, Smyth MJ, Kroemer G. Type I Interferons in Anticancer Immunity. Nat Rev Immunol (2015) 15(7):405-14. doi: 10.1038/ nri3845

184. Melero I, Quetglas JI, Reboredo M, Dubrot J, Rodriguez-Madoz JR, Mancheno U, et al. Strict Requirement for Vector-Induced Type I Interferon in Efficacious Antitumor Responses to Virally Encoded IL12. Cancer Res (2015) 75(3):497-507. doi: 10.1158/0008-5472.CAN-13-3356

185. Froechlich G, Caiazza C, Gentile C, D'Alise AM, De Lucia M, Langone F, et al. Integrity of the Antiviral STING-Mediated DNA Sensing in Tumor Cells Is Required to Sustain the Immunotherapeutic Efficacy of Herpes Simplex Oncolytic Virus. Cancers (Basel) (2020) 12(11):3407. doi: 10.3390/ cancers 12113407

186. Borden EC. Interferons Alpha and Beta in Cancer: Therapeutic Opportunities From New Insights. Nat Rev Drug Discovery (2019) 18 (3):219-34. doi: 10.1038/s41573-018-0011-2

187. Salmon H, Idoyaga J, Rahman A, Leboeuf M, Remark R, Jordan S, et al. Expansion and Activation of CD103(+) Dendritic Cell Progenitors at the Tumor Site Enhances Tumor Responses to Therapeutic PD-L1 and BRAF Inhibition. Immunity (2016) 44(4):924-38. doi: 10.1016/j.immuni.2016.03.012

188. Corrales L, Matson V, Flood B, Spranger S, Gajewski TF. Innate Immune Signaling and Regulation in Cancer Immunotherapy. Cell Res (2017) 27 (1):96-108. doi: 10.1038/cr.2016.149

189. Dabritz J. GM-CSF and the Role of Myeloid Regulatory Cells in the Pathogenesis and Treatment of Crohn's Disease. Mol Cell Pediatr (2015) 2 (1):12. doi: 10.1186/s40348-015-0024-4

190. Jensen H, Andresen L, Nielsen J, Christensen JP, Skov S. Vesicular Stomatitis Virus Infection Promotes Immune Evasion by Preventing NKG2D-Ligand Surface Expression. PloS One (2011) 6(8):e23023. doi: 10.1371/ journal.pone. 0023023

191. Nakatake M, Kurosaki H, Kuwano N, Horita K, Ito M, Kono H, et al. Partial Deletion of Glycoprotein B5R Enhances Vaccinia Virus Neutralization Escape While Preserving Oncolytic Function. Mol Ther Oncolytics (2019) 14:159-71. doi: 10.1016/j.omto.2019.05.003

192. Topkan E, Topuk S, Oymak E, Parlak C, Pehlivan B. Pseudoprogression in Patients With Glioblastoma Multiforme After Concurrent Radiotherapy and Temozolomide. Am J Clin Oncol (2012) 35(3):284-9. doi: 10.1097/ COC.0b013e318210f54a

193. Taal W, Brandsma D, de Bruin HG, Bromberg JE, Swaak-Kragten AT, Smitt PA, et al. Incidence of Early Pseudo-Progression in a Cohort of Malignant Glioma Patients Treated With Chemoirradiation With Temozolomide. Cancer (2008) 113(2):405-10. doi: 10.1002/cncr.23562

194. Watne K, Hager B, Heier M, Hirschberg H. Reversible Oedema and Necrosis After Irradiation of the Brain. Diagnostic Procedures and Clinical Manifestations. Acta Oncol (1990) 29(7):891-5. doi: 10.3109/02841869009096385

195. Chiou VL, Burotto M. Pseudoprogression and Immune-Related Response in Solid Tumors. J Clin Oncol (2015) 33(31):3541-3. doi: 10.1200/JCO.2015.61.6870

196. Calandri M, Solitro F, Angelino V, Moretti F, Veltri A. The Role of Radiology in the Evaluation of the Immunotherapy Efficacy. J Thorac Dis (2018) 10 (Suppl 13):S1438-S46. doi: 10.21037/jtd.2018.05.130

197. Brown MC, Holl EK, Boczkowski D, Dobrikova E, Mosaheb M, Chandramohan V, et al. Cancer Immunotherapy With Recombinant Poliovirus Induces IFN-Dominant Activation of Dendritic Cells and Tumor Antigen-Specific CTLs. Sci Transl Med (2017) 9(408):eaan4220. doi: $10.1126 /$ scitranslmed.aan 4220

198. Delgado-Lopez PD, Rinones-Mena E, Corrales-Garcia EM. TreatmentRelated Changes in Glioblastoma: A Review on the Controversies in Response Assessment Criteria and the Concepts of True Progression, Pseudoprogression, Pseudoresponse and Radionecrosis. Clin Transl Oncol (2018) 20(8):939-53. doi: 10.1007/s12094-017-1816-x

199. Pitter KL, Tamagno I, Alikhanyan K, Hosni-Ahmed A, Pattwell SS, Donnola S, et al. Corticosteroids Compromise Survival in Glioblastoma. Brain (2016) 139(Pt 5):1458-71. doi: 10.1093/brain/aww046
200. Giles AJ, Hutchinson MND, Sonnemann HM, Jung J, Fecci PE, Ratnam NM, et al. Dexamethasone-Induced Immunosuppression: Mechanisms and Implications for Immunotherapy. J Immunother Cancer (2018) 6(1):51. doi: 10.1186/s40425-018-0371-5

201. Eisenhauer EA, Therasse P, Bogaerts J, Schwartz LH, Sargent D, Ford R, et al. New Response Evaluation Criteria in Solid Tumours: Revised RECIST Guideline (Version 1.1). Eur J Cancer (2009) 45(2):228-47. doi: 10.1016/j.ejca.2008.10.026

202. Seymour L, Bogaerts J, Perrone A, Ford R, Schwartz LH, Mandrekar S, et al. iRECIST: Guidelines for Response Criteria for Use in Trials Testing Immunotherapeutics. Lancet Oncol (2017) 18(3):e143-e52. doi: 10.1016/ S1470-2045(17)30074-8

203. Wen PY, Macdonald DR, Reardon DA, Cloughesy TF, Sorensen AG, Galanis E, et al. Updated Response Assessment Criteria for High-Grade Gliomas: Response Assessment in Neuro-Oncology Working Group. J Clin Oncol (2010) 28(11):1963-72. doi: 10.1200/JCO.2009.26.3541

204. Lee J, Wang N, Turk S, Mohammed S, Lobo R, Kim J, et al. Discriminating Pseudoprogression and True Progression in Diffuse Infiltrating Glioma Using Multi-Parametric MRI Data Through Deep Learning. Sci Rep (2020) 10(1):20331. doi: 10.1038/s41598-020-77389-0

205. Kim JY, Park JE, Jo Y, Shim WH, Nam SJ, Kim JH, et al. Incorporating Diffusion- and Perfusion-Weighted MRI Into a Radiomics Model Improves Diagnostic Performance for Pseudoprogression in Glioblastoma Patients. Neuro Oncol (2019) 21(3):404-14. doi: 10.1093/neuonc/noy133

206. Antonios JP, Soto H, Everson RG, Moughon DL, Wang AC, Orpilla J, et al. Detection of Immune Responses After Immunotherapy in Glioblastoma Using. Proc Natl Acad Sci USA (2017) 114(38):10220-5. doi: 10.1073/ pnas. 1706689114

207. Matveeva OV, Chumakov PM. Defects in Interferon Pathways as Potential Biomarkers of Sensitivity to Oncolytic Viruses. Rev Med Virol (2018) 28(6): e2008. doi: 10.1002/rmv.2008

208. Sprooten J, Agostinis P, Garg AD. Type I Interferons and Dendritic Cells in Cancer Immunotherapy. Int Rev Cell Mol Biol (2019) 348:217-62. doi: 10.1016/bs.ircmb.2019.06.001

209. Glas M, Coch C, Trageser D, Dassler J, Simon M, Koch P, et al. Targeting the Cytosolic Innate Immune Receptors RIG-I and MDA5 Effectively Counteracts Cancer Cell Heterogeneity in Glioblastoma. Stem Cells (2013) 31(6):1064-74. doi: 10.1002/stem.1350

210. Besch R, Poeck H, Hohenauer T, Senft D, Hacker G, Berking C, et al. Proapoptotic Signaling Induced by RIG-I and MDA-5 Results in Type I Interferon-Independent Apoptosis in Human Melanoma Cells. J Clin Invest (2009) 119(8):2399-411. doi: 10.1172/JCI37155

211. Elion DL, Jacobson ME, Hicks DJ, Rahman B, Sanchez V, Gonzales-Ericsson PI, et al. Therapeutically Active RIG-I Agonist Induces Immunogenic Tumor Cell Killing in Breast Cancers. Cancer Res (2018) 78(21):6183-95. doi: 10.1158/0008-5472.CAN-18-0730

212. Li D, Gale RP, Liu Y, Lei B, Wang Y, Diao D, et al. 5'-Triphosphate siRNA Targeting MDR1 Reverses Multi-Drug Resistance and Activates RIG-I-Induced Immune-Stimulatory and Apoptotic Effects Against Human Myeloid Leukaemia Cells. Leuk Res (2017) 58:23-30. doi: 10.1016/j.leukres.2017.03.010

213. Vascotto F, Petschenka J, Walzer KC, Vormehr M, Brkic M, Strobl S, et al. Intravenous Delivery of the Toll-Like Receptor 7 Agonist SC1 Confers Tumor Control by Inducing a CD8+ T Cell Response. Oncoimmunology (2019) 8(7):1601480. doi: 10.1080/2162402X.2019.1601480

214. Buonfiglioli A, Efe IE, Guneykaya D, Ivanov A, Huang Y, Orlowski E, et al. Let-7 MicroRNAs Regulate Microglial Function and Suppress Glioma Growth Through Toll-Like Receptor 7. Cell Rep (2019) 29(11):3460-71 e7. doi: 10.1016/j.celrep.2019.11.029

215. Linder A, Bothe V, Linder N, Schwarzlmueller P, Dahlstrom F, Bartenhagen $\mathrm{C}$, et al. Defective Interfering Genomes and the Full-Length Viral Genome Trigger RIG-I After Infection With Vesicular Stomatitis Virus in a Replication Dependent Manner. Front Immunol (2021) 12:595390. doi: 10.3389/fimmu.2021.595390

216. Achard C, Guillerme JB, Bruni D, Boisgerault N, Combredet C, Tangy F, et al. Oncolytic Measles Virus Induces Tumor Necrosis Factor-Related Apoptosis-Inducing Ligand (TRAIL)-Mediated Cytotoxicity by Human Myeloid and Plasmacytoid Dendritic Cells. Oncoimmunology (2017) 6(1): e1261240. doi: 10.1080/2162402X.2016.1261240 
217. An Y, Wang X, Wu X, Chen L, Yang Y, Lin X, et al. Oncolytic Reovirus Induces Ovarian Cancer Cell Apoptosis in a TLR3-Dependent Manner. Virus Res (2021) 301:198440. doi: 10.1016/j.virusres.2021.198440

218. Katayama Y, Tachibana M, Kurisu N, Oya Y, Terasawa Y, Goda H, et al. Oncolytic Reovirus Inhibits Immunosuppressive Activity of MyeloidDerived Suppressor Cells in a TLR3-Dependent Manner. J Immunol (2018) 200(8):2987-99. doi: 10.4049/jimmunol.1700435

219. Sieben M, Schafer P, Dinsart C, Galle PR, Moehler M. Activation of the Human Immune System via Toll-Like Receptors by the Oncolytic Parvovirus H-1. Int J Cancer (2013) 132(11):2548-56. doi: 10.1002/ijc.27938

220. Rommelfanger DM, Compte M, Diaz RM, Ilett E, Alvarez-Vallina L, Thompson JM, et al. The Efficacy Versus Toxicity Profile of Combination Virotherapy and TLR Immunotherapy Highlights the Danger of Administering TLR Agonists to Oncolytic Virus-Treated Mice. Mol Ther (2013) 21(2):348-57. doi: 10.1038/mt.2012.204

221. Deng S, Zhu S, Qiao Y, Liu YJ, Chen W, Zhao G, et al. Recent Advances in the Role of Toll-Like Receptors and TLR Agonists in Immunotherapy for Human Glioma. Protein Cell (2014) 5(12):899-911. doi: 10.1007/s13238-014-0112-6

222. Maleki Vareki S, Garrigos C, Duran I. Biomarkers of Response to PD-1/PDL1 Inhibition. Crit Rev Oncol Hematol (2017) 116:116-24. doi: 10.1016/ j.critrevonc.2017.06.001

223. Matveeva OV, Shabalina SA. Prospects for Using Expression Patterns of Paramyxovirus Receptors as Biomarkers for Oncolytic Virotherapy. Cancers (Basel) (2020) 12(12):3659. doi: 10.3390/cancers12123659

224. Stavrakaki E, Dirven CMF, Lamfers MLM. Personalizing Oncolytic Virotherapy for Glioblastoma: In Search of Biomarkers for Response. Cancers (Basel) (2021) 13(4):614. doi: 10.3390/cancers13040614

225. Akter F, Simon B, de Boer NL, Redjal N, Wakimoto H, Shah K. Pre-Clinical Tumor Models of Primary Brain Tumors: Challenges and Opportunities. Biochim Biophys Acta Rev Cancer (2021) 1875(1):188458. doi: 10.1016/j.bbcan.2020.188458

226. Sibenaller ZA, Etame AB, Ali MM, Barua M, Braun TA, Casavant TL, et al. Genetic Characterization of Commonly Used Glioma Cell Lines in the Rat Animal Model System. Neurosurg Focus (2005) 19(4):E1. doi: 10.3171/foc.2005.19.4.2

227. von Werder A, Seidler B, Schmid RM, Schneider G, Saur D. Production of Avian Retroviruses and Tissue-Specific Somatic Retroviral Gene Transfer In Vivo Using the RCAS/TVA System. Nat Protoc (2012) 7(6):1167-83. doi: 10.1038/nprot.2012.060

228. Vaubel RA, Tian S, Remonde D, Schroeder MA, Mladek AC, Kitange GJ, et al. Genomic and Phenotypic Characterization of a Broad Panel of PatientDerived Xenografts Reflects the Diversity of Glioblastoma. Clin Cancer Res (2020) 26(5):1094-104. doi: 10.1158/1078-0432.CCR-19-0909

229. Clement V, Dutoit V, Marino D, Dietrich PY, Radovanovic I. Limits of CD133 as a Marker of Glioma Self-Renewing Cells. Int J Cancer (2009) 125 (1):244-8. doi: 10.1002/ijc.24352

230. Luchman HA, Chesnelong C, Cairncross JG, Weiss S. Spontaneous Loss of Heterozygosity Leading to Homozygous R132H in a Patient-Derived IDH1 Mutant Cell Line. Neuro Oncol (2013) 15(8):979-80. doi: 10.1093/neuonc/not064

231. Kauer TM, Figueiredo JL, Hingtgen S, Shah K. Encapsulated Therapeutic Stem Cells Implanted in the Tumor Resection Cavity Induce Cell Death in Gliomas. Nat Neurosci (2011) 15(2):197-204. doi: 10.1038/nn.3019

232. Li A, Walling J, Kotliarov Y, Center A, Steed ME, Ahn SJ, et al. Genomic Changes and Gene Expression Profiles Reveal That Established Glioma Cell Lines are Poorly Representative of Primary Human Gliomas. Mol Cancer Res (2008) 6(1):21-30. doi: 10.1158/1541-7786.MCR-07-0280

233. Robinson M, Li B, Ge Y, Ko D, Yendluri S, Harding T, et al. Novel Immunocompetent Murine Tumor Model for Evaluation of Conditionally Replication-Competent (Oncolytic) Murine Adenoviral Vectors. J Virol (2009) 83(8):3450-62. doi: 10.1128/JVI.02561-08

234. Vittori M, Motaln H, Turnsek TL. The Study of Glioma by Xenotransplantation in Zebrafish Early Life Stages. J Histochem Cytochem (2015) 63(10):749-61. doi: 10.1369/0022155415595670

235. Witte HT, Jeibmann A, Klambt C, Paulus W. Modeling Glioma Growth and Invasion in Drosophila Melanogaster. Neoplasia (2009) 11(9):882-8. doi: $10.1593 /$ neo.09576

236. Linkous A, Balamatsias D, Snuderl M, Edwards L, Miyaguchi K, Milner T, et al. Modeling Patient-Derived Glioblastoma With Cerebral Organoids. Cell Rep (2019) 26(12):3203-11.e5. doi: 10.1016/j.celrep.2019.02.063
237. Young JS, Bernal G, Polster SP, Nunez L, Larsen GF, Mansour N, et al. Convection-Enhanced Delivery of Polymeric Nanoparticles Encapsulating Chemotherapy in Canines With Spontaneous Supratentorial Tumors. World Neurosurg (2018) 117:e698-704. doi: 10.1016/j.wneu.2018.06.114

238. Chiocca EA, Nassiri F, Wang J, Peruzzi P, Zadeh G. Viral and Other Therapies for Recurrent Glioblastoma: Is a 24-Month Durable Response Unusual? Neuro Oncol (2019) 21(1):14-25. doi: 10.1093/neuonc/noy170

239. Westphal M, Black PM. Perspectives of Cellular and Molecular Neurosurgery. J Neurooncol (2004) 70(2):255-69. doi: 10.1007/s11060-004-2754-3

240. Carpenter AB, Carpenter AM, Aiken R, Hanft S. Oncolytic Virus in Gliomas: A Review of Human Clinical Investigations. Ann Oncol (2021) 32(8):968-82. doi: 10.1016/j.annonc.2021.03.197

241. Spranger S, Dai D, Horton B, Gajewski TF. Tumor-Residing Batf3 Dendritic Cells Are Required for Effector T Cell Trafficking and Adoptive T Cell Therapy. Cancer Cell (2017) 31(5):711-23.e4. doi: 10.1016/j.ccell.2017.04.003

242. Voges J, Reszka R, Gossmann A, Dittmar C, Richter R, Garlip G, et al. Imaging-Guided Convection-Enhanced Delivery and Gene Therapy of Glioblastoma. Ann Neurol (2003) 54(4):479-87. doi: 10.1002/ana.10688

243. Lichty BD, Breitbach CJ, Stojdl DF, Bell JC. Going Viral With Cancer Immunotherapy. Nat Rev Cancer (2014) 14(8):559-67. doi: 10.1038/nrc3770

244. Beccaria K, Canney M, Bouchoux G, Desseaux C, Grill J, Heimberger AB, et al. Ultrasound-Induced Blood-Brain Barrier Disruption for the Treatment of Gliomas and Other Primary CNS Tumors. Cancer Lett (2020) 479:13-22. doi: 10.1016/j.canlet.2020.02.013

245. Carpentier A, Canney M, Vignot A, Reina V, Beccaria K, Horodyckid C, et al. Clinical Trial of Blood-Brain Barrier Disruption by Pulsed Ultrasound. Sci Transl Med (2016) 8(343):343re2. doi: 10.1126/scitranslmed.aaf6086

246. Gasca-Salas C, Fernandez-Rodriguez B, Pineda-Pardo JA, Rodriguez-Rojas R, Obeso I, Hernandez-Fernandez F, et al. Blood-Brain Barrier Opening With Focused Ultrasound in Parkinson's Disease Dementia. Nat Commun (2021) 12(1):779. doi: 10.1038/s41467-021-21022-9

247. Ilett E, Kottke T, Donnelly O, Thompson J, Willmon C, Diaz R, et al. Cytokine Conditioning Enhances Systemic Delivery and Therapy of an Oncolytic Virus. Mol Ther (2014) 22(10):1851-63. doi: 10.1038/mt.2014.118

248. Rahn JJ, Lun X, Jorch SK, Hao X, Venugopal C, Vora P, et al. Development of a Peptide-Based Delivery Platform for Targeting Malignant Brain Tumors. Biomaterials (2020) 252:120105. doi: 10.1016/j.biomaterials.2020.120105

249. Totsch SK, Schlappi C, Kang KD, Ishizuka AS, Lynn GM, Fox B, et al. Oncolytic Herpes Simplex Virus Immunotherapy for Brain Tumors: Current Pitfalls and Emerging Strategies to Overcome Therapeutic Resistance. Oncogene (2019) 38(34):6159-71. doi: 10.1038/s41388-019-0870-y

250. Vaha-Koskela M, Hinkkanen A. Tumor Restrictions to Oncolytic Virus. Biomedicines (2014) 2(2):163-94. doi: 10.3390/biomedicines2020163

251. Prins RM, Liau LM. Immunology and Immunotherapy in Neurosurgical Disease. Neurosurgery (2003) 53(1):144-52. doi: 10.1227/01.neu.0000068865.34216.3a discussion 52-3.

252. Sivanandam V, LaRocca CJ, Chen NG, Fong Y, Warner SG. Oncolytic Viruses and Immune Checkpoint Inhibition: The Best of Both Worlds. Mol Ther Oncolytics (2019) 13:93-106. doi: 10.1016/j.omto.2019.04.003

253. Chesney J, Puzanov I, Collichio F, Singh P, Milhem MM, Glaspy J, et al. Randomized, Open-Label Phase II Study Evaluating the Efficacy and Safety of Talimogene Laherparepvec in Combination With Ipilimumab Versus Ipilimumab Alone in Patients With Advanced, Unresectable Melanoma. J Clin Oncol (2018) 36(17):1658-67. doi: 10.1200/JCO.2017.73.7379

254. Wright JJ, Powers AC, Johnson DB. Endocrine Toxicities of Immune Checkpoint Inhibitors. Nat Rev Endocrinol (2021) 17(7):389-99. doi: 10.1038/s41574-021-00484-3

255. Reardon DA, Brandes AA, Omuro A, Mulholland P, Lim M, Wick A, et al. Effect of Nivolumab vs Bevacizumab in Patients With Recurrent Glioblastoma: The CheckMate 143 Phase 3 Randomized Clinical Trial. JAMA Oncol (2020) 6(7):1003-10. doi: 10.1001/jamaoncol.2020.1024

256. Bourgeois-Daigneault MC, Roy DG, Aitken AS, El Sayes N, Martin NT, Varette $\mathrm{O}$, et al. Neoadjuvant Oncolytic Virotherapy Before Surgery Sensitizes Triple-Negative Breast Cancer to Immune Checkpoint Therapy. Sci Transl Med (2018) 10(422):eaao1641. doi: 10.1126/scitranslmed.aao1641

257. Wang G, Kang X, Chen KS, Jehng T, Jones L, Chen J, et al. An Engineered Oncolytic Virus Expressing PD-L1 Inhibitors Activates Tumor Neoantigen- 
Specific T Cell Responses. Nat Commun (2020) 11(1):1395. doi: 10.1038/ s41467-020-15229-5

258. Jiang H, Rivera-Molina Y, Gomez-Manzano C, Clise-Dwyer K, Bover L, Vence LM, et al. Oncolytic Adenovirus and Tumor-Targeting Immune Modulatory Therapy Improve Autologous Cancer Vaccination. Cancer Res (2017) 77(14):3894-907. doi: 10.1158/0008-5472.CAN-17-0468

259. Saha D, Martuza RL, Rabkin SD. Macrophage Polarization Contributes to Glioblastoma Eradication by Combination Immunovirotherapy and Immune Checkpoint Blockade. Cancer Cell (2017) 32(2):253-67 e5. doi: 10.1016/j.ccell.2017.07.006

260. Cockle JV, Rajani K, Zaidi S, Kottke T, Thompson J, Diaz RM, et al. Combination Viroimmunotherapy With Checkpoint Inhibition to Treat Glioma, Based on Location-Specific Tumor Profiling. Neuro Oncol (2016) 18(4):518-27. doi: 10.1093/neuonc/nov173

261. Cloughesy TF, Mochizuki AY, Orpilla JR, Hugo W, Lee AH, Davidson TB, et al. Neoadjuvant Anti-PD-1 Immunotherapy Promotes a Survival Benefit With Intratumoral and Systemic Immune Responses in Recurrent Glioblastoma. Nat Med (2019) 25(3):477-86. doi: 10.1038/s41591-0180337-7

262. Schumacher T, Bunse L, Pusch S, Sahm F, Wiestler B, Quandt J, et al. A Vaccine Targeting Mutant IDH1 Induces Antitumour Immunity. Nature (2014) 512(7514):324-7. doi: 10.1038/nature13387

263. Ichikawa K, Kagamu H, Koyama K, Miyabayashi T, Koshio J, Miura S, et al. Epitope Diversification Driven by non-Tumor Epitope-Specific Th1 and Th17 Mediates Potent Antitumor Reactivity. Vaccine (2012) 30(43):6190-7. doi: $10.1016 /$ j.vaccine.2012.07.060

264. Russell SJ, Barber GN. Oncolytic Viruses as Antigen-Agnostic Cancer Vaccines. Cancer Cell (2018) 33(4):599-605. doi: 10.1016/j.ccell.2018.03.011

265. Okada H, Kalinski P, Ueda R, Hoji A, Kohanbash G, Donegan TE, et al. Induction of CD8+ T-Cell Responses Against Novel Glioma-Associated Antigen Peptides and Clinical Activity by Vaccinations With \{Alpha\}Type 1 Polarized Dendritic Cells and Polyinosinic-Polycytidylic Acid Stabilized by Lysine and Carboxymethylcellulose in Patients With Recurrent Malignant Glioma. J Clin Oncol (2011) 29(3):330-6. doi: $10.1200 / J C O .2010 .30 .7744$

266. Phuphanich S, Wheeler CJ, Rudnick JD, Mazer M, Wang H, Nuno MA, et al. Phase I Trial of a Multi-Epitope-Pulsed Dendritic Cell Vaccine for Patients With Newly Diagnosed Glioblastoma. Cancer Immunol Immunother (2013) 62(1):125-35. doi: 10.1007/s00262-012-1319-0

267. Wen PY, Reardon DA, Armstrong TS, Phuphanich S, Aiken RD, Landolfi JC, et al. A Randomized Double-Blind Placebo-Controlled Phase II Trial of Dendritic Cell Vaccine ICT-107 in Newly Diagnosed Patients With Glioblastoma. Clin Cancer Res (2019) 25(19):5799-807. doi: 10.1158/10780432.CCR-19-0261

268. Van Brussel I, Berneman ZN, Cools N. Optimizing Dendritic Cell-Based Immunotherapy: Tackling the Complexity of Different Arms of the Immune System. Mediators Inflamm (2012) 2012:690643. doi: 10.1155/2012/690643

269. Farrell CJ, Zaupa C, Barnard Z, Maley J, Martuza RL, Rabkin SD, et al. Combination Immunotherapy for Tumors via Sequential Intratumoral Injections of Oncolytic Herpes Simplex Virus 1 and Immature Dendritic Cells. Clin Cancer Res (2008) 14(23):7711-6. doi: 10.1158/1078-0432.CCR-08-1364

270. Li J, O’Malley M, Urban J, Sampath P, Guo ZS, Kalinski P, et al. Chemokine Expression From Oncolytic Vaccinia Virus Enhances Vaccine Therapies of Cancer. Mol Ther (2011) 19(4):650-7. doi: 10.1038/mt.2010.312

271. Koske I, Rossler A, Pipperger L, Petersson M, Barnstorf I, Kimpel J, et al. Oncolytic Virotherapy Enhances the Efficacy of a Cancer Vaccine by Modulating the Tumor Microenvironment. Int J Cancer (2019) 145 (7):1958-69. doi: 10.1002/ijc.32325

272. Zhang SN, Choi IK, Huang JH, Yoo JY, Choi KJ, Yun CO. Optimizing DC Vaccination by Combination With Oncolytic Adenovirus Coexpressing IL12 and GM-CSF. Mol Ther (2011) 19(8):1558-68. doi: 10.1038/mt.2011.29

273. Zafar S, Basnet S, Launonen IM, Quixabeira DCA, Santos J, Hemminki O, et al. Oncolytic Adenovirus Type 3 Coding for CD40L Facilitates Dendritic Cell Therapy of Prostate Cancer in Humanized Mice and Patient Samples. Hum Gene Ther (2021) 32(3-4):192-202. doi: 10.1089/hum.2020.222

274. Sampson JH, Heimberger AB, Archer GE, Aldape KD, Friedman AH, Friedman HS, et al. Immunologic Escape After Prolonged ProgressionFree Survival With Epidermal Growth Factor Receptor Variant III Peptide
Vaccination in Patients With Newly Diagnosed Glioblastoma. J Clin Oncol (2010) 28(31):4722-9. doi: 10.1200/JCO.2010.28.6963

275. Oji Y, Hashimoto N, Tsuboi A, Murakami Y, Iwai M, Kagawa N, et al. Association of WT1 IgG Antibody Against WT1 Peptide With Prolonged Survival in Glioblastoma Multiforme Patients Vaccinated With WT1 Peptide. Int J Cancer (2016) 139(6):1391-401. doi: 10.1002/ijc.30182

276. Atherton MJ, Stephenson KB, Nikota JK, Hu QN, Nguyen A, Wan Y, et al. Preclinical Development of Peptide Vaccination Combined With Oncolytic MG1-E6E7 for HPV-Associated Cancer. Vaccine (2018) 36(16):2181-92. doi: 10.1016/j.vaccine.2018.02.070

277. Pollack IF, Jakacki RI, Butterfield LH, Hamilton RL, Panigrahy A, Potter DM, et al. Antigen-Specific Immune Responses and Clinical Outcome After Vaccination With Glioma-Associated Antigen Peptides and PolyinosinicPolycytidylic Acid Stabilized by Lysine and Carboxymethylcellulose in Children With Newly Diagnosed Malignant Brainstem and Nonbrainstem Gliomas. J Clin Oncol (2014) 32(19):2050-8. doi: 10.1200/JCO.2013.54.0526

278. Rampling R, Peoples S, Mulholland PJ, James A, Al-Salihi O, Twelves CJ, et al. A Cancer Research UK First Time in Human Phase I Trial of IMA950 (Novel Multipeptide Therapeutic Vaccine) in Patients With Newly Diagnosed Glioblastoma. Clin Cancer Res (2016) 22(19):4776-85. doi: 10.1158/1078-0432.CCR-16-0506

279. Keskin DB, Anandappa AJ, Sun J, Tirosh I, Mathewson ND, Li S, et al. Neoantigen Vaccine Generates Intratumoral T Cell Responses in Phase Ib Glioblastoma Trial. Nature (2019) 565(7738):234-9. doi: 10.1038/s41586-018-0792-9

280. Schuessler A, Smith C, Beagley L, Boyle GM, Rehan S, Matthews K, et al. Autologous T-Cell Therapy for Cytomegalovirus as a Consolidative Treatment for Recurrent Glioblastoma. Cancer Res (2014) 74(13):3466-76. doi: 10.1158/0008-5472.CAN-14-0296

281. Long KB, Young RM, Boesteanu AC, Davis MM, Melenhorst JJ, Lacey SF, et al. CAR T Cell Therapy of Non-Hematopoietic Malignancies: Detours on the Road to Clinical Success. Front Immunol (2018) 9:2740. doi: 10.3389/ fimmu.2018.02740

282. O’Rourke DM, Nasrallah MP, Desai A, Melenhorst JJ, Mansfield K, Morrissette JJD, et al. A Single Dose of Peripherally Infused EGFRvIIIDirected CAR T Cells Mediates Antigen Loss and Induces Adaptive Resistance in Patients With Recurrent Glioblastoma. Sci Transl Med (2017) 9(399):eaaa0984. doi: 10.1126/scitranslmed.aaa0984

283. Ahmed N, Brawley V, Hegde M, Bielamowicz K, Kalra M, Landi D, et al. HER2-Specific Chimeric Antigen Receptor-Modified Virus-Specific T Cells for Progressive Glioblastoma: A Phase 1 Dose-Escalation Trial. JAMA Oncol (2017) 3(8):1094-101. doi: 10.1001/jamaoncol.2017.0184

284. Kershaw MH, Westwood JA, Parker LL, Wang G, Eshhar Z, Mavroukakis SA, et al. A Phase I Study on Adoptive Immunotherapy Using GeneModified T Cells for Ovarian Cancer. Clin Cancer Res (2006) 12(20 Pt 1):6106-15. doi: 10.1158/1078-0432.CCR-06-1183

285. Huang J, Zheng M, Zhang Z, Tang X, Chen Y, Peng A, et al. Interleukin-7Loaded Oncolytic Adenovirus Improves CAR-T Cell Therapy for Glioblastoma. Cancer Immunol Immunother (2021) 70(9):2453-65. doi: 10.1007/s00262-02102856-0

286. Ajina A, Maher J. Prospects for Combined Use of Oncolytic Viruses and CAR TCells. J Immunother Cancer (2017) 5(1):90. doi: 10.1186/s40425-017-0294-6

287. Nishio N, Dotti G. Oncolytic Virus Expressing RANTES and IL-15 Enhances Function of CAR-Modified T Cells in Solid Tumors. Oncoimmunology (2015) 4(2):e988098. doi: 10.4161/21505594.2014.988098

288. Nishio N, Diaconu I, Liu H, Cerullo V, Caruana I, Hoyos V, et al. Armed Oncolytic Virus Enhances Immune Functions of Chimeric Antigen Receptor-Modified T Cells in Solid Tumors. Cancer Res (2014) 74 (18):5195-205. doi: 10.1158/0008-5472.CAN-14-0697

289. Evgin L, Huff AL, Wongthida P, Thompson J, Kottke T, Tonne J, et al. Oncolytic Virus-Derived Type I Interferon Restricts CAR T Cell Therapy. Nat Commun (2020) 11(1):3187. doi: 10.1038/s41467-020-17011-z

290. Moon EK, Wang LS, Bekdache K, Lynn RC, Lo A, Thorne SH, et al. IntraTumoral Delivery of CXCL11 via a Vaccinia Virus, But Not by Modified T Cells, Enhances the Efficacy of Adoptive T Cell Therapy and Vaccines. Oncoimmunology (2018) 7(3):e1395997. doi: 10.1080/2162402X.2017.1395997

291. Berraondo P, Etxeberria I, Ponz-Sarvise M, Melero I. Revisiting Interleukin12 as a Cancer Immunotherapy Agent. Clin Cancer Res (2018) 24(12):27168. doi: 10.1158/1078-0432.CCR-18-0381 
292. Nguyen HM, Guz-Montgomery K, Saha D. Oncolytic Virus Encoding a Master Pro-Inflammatory Cytokine Interleukin 12 in Cancer Immunotherapy. Cells (2020) 9(2):400. doi: 10.3390/cells9020400

293. Poutou J, Bunuales M, Gonzalez-Aparicio M, Garcia-Aragoncillo E, Quetglas JI, Casado R, et al. Safety and Antitumor Effect of Oncolytic and Helper-Dependent Adenoviruses Expressing Interleukin-12 Variants in a Hamster Pancreatic Cancer Model. Gene Ther (2015) 22(9):696-706. doi: 10.1038/gt.2015.45

294. Roth JC, Cassady KA, Cody JJ, Parker JN, Price KH, Coleman JM, et al. Evaluation of the Safety and Biodistribution of M032, an Attenuated Herpes Simplex Virus Type 1 Expressing hIL-12, After Intracerebral Administration to Aotus Nonhuman Primates. Hum Gene Ther Clin Dev (2014) 25(1):16-27. doi: 10.1089/humc.2013.201

295. Martin NT, Bell JC. Oncolytic Virus Combination Therapy: Killing One Bird With Two Stones. Mol Ther (2018) 26(6):1414-22. doi: 10.1016/j.ymthe.2018.04.001

296. Ren J, Gwin WR, Zhou X, Wang X, Huang H, Jiang N, et al. Adaptive T Cell Responses Induced by Oncolytic Herpes Simplex Virus-Granulocyte Macrophage-Colony-Stimulating Factor Therapy Expanded by Dendritic Cell and Cytokine-Induced Killer Cell Adoptive Therapy. Oncoimmunology (2017) 6 (4):e1264563. doi: 10.1080/2162402X.2016.1264563

297. Stephenson KB, Barra NG, Davies E, Ashkar AA, Lichty BD. Expressing Human Interleukin-15 From Oncolytic Vesicular Stomatitis Virus Improves Survival in a Murine Metastatic Colon Adenocarcinoma Model Through the Enhancement of Anti-Tumor Immunity. Cancer Gene Ther (2012) 19 (4):238-46. doi: 10.1038/cgt.2011.81

298. Bourgeois-Daigneault MC, Roy DG, Falls T, Twumasi-Boateng K, StGermain LE, Marguerie M, et al. Oncolytic Vesicular Stomatitis Virus Expressing Interferon-Gamma has Enhanced Therapeutic Activity. Mol Ther Oncolytics (2016) 3:16001. doi: 10.1038/mto.2016.1

299. Zhang J, Tai LH, Ilkow CS, Alkayyal AA, Ananth AA, de Souza CT, et al. Maraba MG1 Virus Enhances Natural Killer Cell Function via Conventional Dendritic Cells to Reduce Postoperative Metastatic Disease. Mol Ther (2014) 22(7):1320-32. doi: 10.1038/mt.2014.60

300. Yan Y, Li S, Jia T, Du X, Xu Y, Zhao Y, et al. Combined Therapy With CTL Cells and Oncolytic Adenovirus Expressing IL-15-Induced Enhanced Antitumor Activity. Tumour Biol (2015) 36(6):4535-43. doi: 10.1007/s13277-015-3098-7

301. Patel DM, Foreman PM, Nabors LB, Riley KO, Gillespie GY, Markert JM. Design of a Phase I Clinical Trial to Evaluate M032, a Genetically Engineered
HSV-1 Expressing IL-12, in Patients With Recurrent/Progressive Glioblastoma Multiforme, Anaplastic Astrocytoma, or Gliosarcoma. Hum Gene Ther Clin Dev (2016) 27(2):69-78. doi: 10.1089/humc.2016.031

302. He QF, Xu Y, Li J, Huang ZM, Li XH, Wang X. CD8+ T-Cell Exhaustion in Cancer: Mechanisms and New Area for Cancer Immunotherapy. Brief Funct Genomics (2019) 18(2):99-106. doi: 10.1093/bfgp/ely006

303. Woroniecka K, Chongsathidkiet P, Rhodin K, Kemeny H, Dechant C, Farber $\mathrm{SH}$, et al. T-Cell Exhaustion Signatures Vary With Tumor Type and Are Severe in Glioblastoma. Clin Cancer Res (2018) 24(17):4175-86. doi: 10.1158/1078-0432.CCR-17-1846

304. Grill J, Lamfers ML, van Beusechem VW, Dirven CM, Pherai DS, Kater M, et al. The Organotypic Multicellular Spheroid Is a Relevant Three-Dimensional Model to Study Adenovirus Replication and Penetration in Human Tumors In Vitro. Mol Ther (2002) 6(5):609-14. doi: 10.1006/mthe.2002.0713

305. Lukas RV, Wainwright DA, Horbinski CM, Iwamoto FM, Sonabend AM. Immunotherapy Against Gliomas: Is the Breakthrough Near? Drugs (2019) 79(17):1839-48. doi: 10.1007/s40265-019-01203-z

Conflict of Interest: Author MS was employed by company Guangzhou Virotech Pharmaceutical Co., Ltd.

The remaining authors declare that the research was conducted in the absence of any commercial or financial relationships that could be construed as a potential conflict of interest.

Publisher's Note: All claims expressed in this article are solely those of the authors and do not necessarily represent those of their affiliated organizations, or those of the publisher, the editors and the reviewers. Any product that may be evaluated in this article, or claim that may be made by its manufacturer, is not guaranteed or endorsed by the publisher.

Copyright (C) 2021 Zeng, Li, Sander, Zhang, Yan and Lin. This is an open-access article distributed under the terms of the Creative Commons Attribution License (CC BY). The use, distribution or reproduction in other forums is permitted, provided the original author(s) and the copyright owner(s) are credited and that the original publication in this journal is cited, in accordance with accepted academic practice. No use, distribution or reproduction is permitted which does not comply with these terms. 